PNL-3575

UC-62

\title{
Adhesion and Chemical Vapor Testing of Second Surface Silver/Glass Solar Mirrors
}

L. S. Dake

M. A. Lind

September 1980

Prepared for

Sandia National Laboratories

Livermore, California

under Related Services Agreement

300A01406 and the U.S. Department of

Energy under Contract DE-AC06-76RLO 1830

\section{* Battelle}




\title{
NOTICE
}

This report was prepared as an account of work sponsored by the United States Government. Neither the United States nor the Department of Energy, nor any of their employees, nor any of their contractors, subcontractors, or their employees, makes any warranty, express or implied, or assumes any legal liability or responsibility for the accuracy. completeness or usefulness of any information, apparatus, product or process disclosed, or represents that its use would not infringe privately owned rights.

The views, opinions and conclusions contained in this report are those of the contractor and do not necessarily represent those of the United States Government or the United States Department of Energy.

\author{
PACIFIC NORTHWEST LABORATORY \\ operated by \\ BATTELLE \\ for the \\ UNITED STATES DEPARTMENT OF ENERGY \\ Under Contract DE-AC06-76RLO 1830
}
Printed in the United States of America Available from
National Technical Information Service United States Department of Commerce 5285 Port Royal Road
Springfield. Virginia 22151

Price: Printed Copy 5 $\because$ Microfiche 53.00

NTIS

*Pages Selling Price

$\begin{array}{ll}001-025 & \$ 4.00 \\ 026-050 & \$ 4.50 \\ 051-075 & \$ 5.25 \\ 076-100 & \$ 6.00 \\ 101-125 & \$ 6.50 \\ 126-150 & \$ 7.25 \\ 151-175 & \$ 8.00 \\ 176-200 & \$ 9.00 \\ 201-225 & \$ 9.25 \\ 226-250 & \$ 9.50 \\ 251-275 & \$ 10.75 \\ 276-300 & \$ 11.00\end{array}$


ADHESION AND CHEMICAL VAPOR TESTING

OF SECOND SURFACE SILVER/GLASS

SOLAR MIRRORS

L. S. Dake

M. A. Lind

September 1980

Prepared for

Sandia National Laboratories Livermore, California under Related Services Agreement 300A01406 and the U.S. Department of Energy under Contract DE-AC06-76RLO 1830

Pacific Northwest Laboratory

Richiand, Washington 99352 


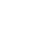
. 


\section{FOREWORD}

This report is the result of technical analysis performed for Sandia National Laboratories and authorized under Sandia Livermore Laboratories Federal Agency Order 92-8522 in support of the U.S. Department of Energy Solar Thermal Large Power Systems Project. The purpose of the work reported here was to provide a preliminary look into comparative testing of wet process silver/glass mirrors for durability screening. 


\section{SUMMARY AND CONCLUSIONS}

Second surface silvered glass mirrors supplied by four different commercial manufacturers were evaluated for silver-to-glass adhesion and resistance to chemical vapor attack. The mirrors were chemically silvered on identical substrates of low iron float glass. The experiments described in this report were performed in order to assess the viability of using adhesion and chemical attack as screening tests for predicting the relative long-term durability of solar mirrors. The results of these tests will be compared at a future time with the survivability of field mirrors deployed in stationary exposure racks at ten locations throughout the United States.

The adhesion tests were performed using a commercially-available thin film tensile pull tester in which a stud bonded to the film is pulled and the yield load recorded. Numerous subtleties regarding the selection of the adhesive used to bond the stud and the validity of the testing procedure are discussed. Several different methods of normalizing the results were attempted in an effort to reduce the scatter in the data. In general, the sample-to-sample variability in the adhesion strength data prevented any meaningful comparison of the mirrors supplied by the four different manufacturers. Significant trends on the relative amount of silver pulled from the substrate by the stud did develop. The reasons for the large amount of scatter in the adhesion data and differences in the amount of silver pulled have not been identified.

The same set of samples were exposed to salt spray, water, $\mathrm{HCl}, \mathrm{H}_{2} \mathrm{SO}_{4}$, and $\mathrm{HNO}_{3}$ vapors and then ranked according to their performance. Visual comparison of tested samples did not yield totally consistent results; however, definite trends were observed favoring one of the manufacturers. Some SEM/EDX analysis was performed on these mirrors subject to accelerated degradation in order to compare them to mirrors subject to "natural" degradation. However, insufficient data has been collected to show that any of the tests performed will accurately predict the relative life expectancy of the mirrors in an outdoor environment or that any of the tests actually stress the samples in a manner similar to the real environment. 


\section{ACKNOWLEDGEMENTS}

The authors wish to express their appreciation to K. Mallory, D. Nelson, and T. Stewart for their laboratory assistance. They also thank J. Hartman and L. Daniel for their many helpful discussions and J. Coleman for the SEM work. The generous cooperation of Binswanger Mirror Products, Carolina Mirror Corporation, Falconer Glass Industries, Inc., Gardner Mirror Corporation, and London Laboratories Limited in supplying samples, materials and advice is greatly appreciated. Conversations with V. Burolla, J. Shelby and J. Vitko of Sandia National Laboratories at Livermore on adhesion tests and chemical compatability testing were very helpful. 


\section{CONTENTS}

\begin{tabular}{|c|c|c|c|c|c|c|c|c|c|c|c|c|}
\hline FOREWORD . & $\cdot$ & $\cdot$ & $\cdot$ & $\cdot$ & $\cdot$ & • & - & • & • & $\cdot$ & . & $\mathrm{i} \mathbf{i}$ \\
\hline SUMMARY AND CONCLUS & IONS & - & $\cdot$ & • & $\cdot$ & - & • & • & ${ }^{\circ}$ & $\cdot$ & 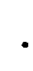 & $v$ \\
\hline ACKNOWLEDGEMENTS & . & - & . & • & . & - & • & • & • & • & • & vi \\
\hline LIST OF FIGURES & $\cdot$ & • & $\cdot$ & $\cdot$ & - & - & - & • & - & $\cdot$ & • & vii \\
\hline LIST OF TABLES . & . & - & . & - & - & - & - & • & - & • & . & $i x$ \\
\hline ADHESION TESTING & - & - & . & - & - & - & - & • & - & $\cdot$ & $\cdot$ & 1 \\
\hline Apparatus. & . & . & . & • & . & - & • & - & - & • & • & 1 \\
\hline Sample Preparat & tion & . & . & - & . & - & - & • & - & • & • & 2 \\
\hline Stud Bonding & . & . & . & • & . & - & - & • & • & • & • & 3 \\
\hline Experimenta $1 \mathrm{Re}$ & esults & & - & • & . & - & • & • & • & • & • & 5 \\
\hline Validity of the & e Test & & - & - & . & - & - & • & - & • & • & 14 \\
\hline Conclusion & - & - & . & $\cdot$ & $\cdot$ & - & - & • & - & $\cdot$ & • & 20 \\
\hline CHEMICAL VAPOR TESTS & & • & . & $\cdot$ & . & - & - & . & - & • & • & 21 \\
\hline Boiling Water & - & · & - & $\cdot$ & $\cdot$ & - & - & • & • & $\cdot$ & • & 22 \\
\hline Salt Spray & . & . & . & - & . & - & - & • & • & • & $\cdot$ & 24 \\
\hline Acid Vapor & - & - & - & $\bullet$ & - & - & - & • & - & • & • & 24 \\
\hline $\mathrm{HCl}$ - & . & . & . & $\cdot$ & . & - & - & • & - & $\cdot$ & • & 35 \\
\hline $\mathrm{H}_{2} \mathrm{SO}_{4}$ & - & $\cdot$ & - & $\cdot$ & $\cdot$ & - & - & • & - & $\cdot$ & ${ }^{\circ}$ & 5 \\
\hline $\mathrm{HNO}_{3}$ & - & $\cdot$ & - & $\cdot$ & . & - & - & • & - & $\cdot$ & ${ }^{\circ}$ & \\
\hline Conclusion & - & . & - & $\bullet$ & - & - & - & • & - & $\cdot$ & . & 41 \\
\hline CONCLUSIONS AND REC & OMMEND & DATION & & - & . & - & • & • & . & - & $\bullet$ & 46 \\
\hline REFERENCES & . & . & . & . & . & . & . & - & . & • & • & \\
\hline
\end{tabular}




\section{LIST OF FIGURES}

Figure

Page

1. Mirror Sample with Stud Attached . . . . . . 2

2. Reflected Light Photograph of the Area Surrounding and

Under the Stud after Heat Cure . . . . . . . 4

3. Adhesive Bond Strength Ranges . . . . . . . 7

4. Transmitted Light Photograph of Area Surrounding

the Stud after Tensile Pull Test . . . . . . 8

5. Percent of Mirror Samples Tested that had

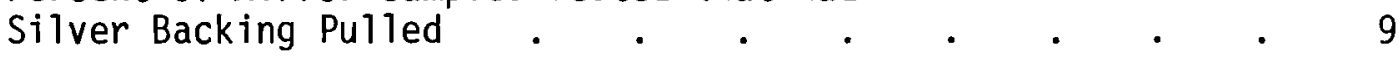

6. Tensile Pull Test Results for Cu-Ag Backed Mirror Samples . 9

7. Area Normalized Yield Load for FT Samples . . . . . 11

8. Area Nomalized Yield Load for FA Samples . . . . . 11

9. Area Normalized Yield Load for B Samples . . . . $\quad$. 12

10. Area Normalized Yield Load for C Samples . . . . 12

11. Area Normalized Yield Load for G Samples _ . . $\quad$ • $\quad 13$

12. Area Normalized Yield Load for FA Samples . $\quad$ • $\quad$ • 15

13. Area Normalized Yield Load for FT Samples . . . . 15

14. Effect of Elevated Temperature Cure on Mirror Samples . . 18

15. Mirror Samples Before and After Partial Immersion

in Boiling $\mathrm{H}_{2} \mathrm{O}$.

16. One Percent Solution Salt Spray Test _ . . . . . $\quad$ • 25

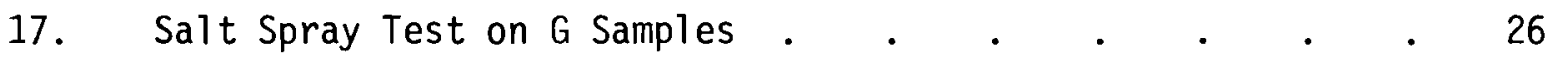

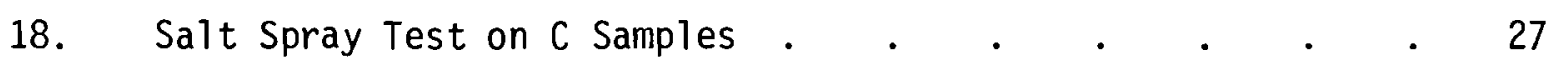

19. Salt Spray Test on B Samples .

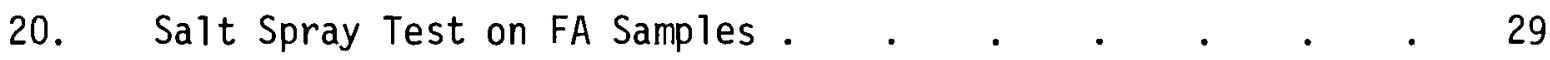

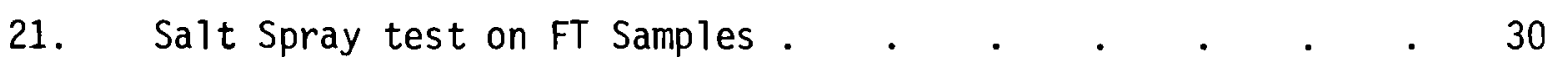




\section{LIST OF FIGURES (continued)}

22. Effect of Acid Vapors on the Paint/Copper/Silver

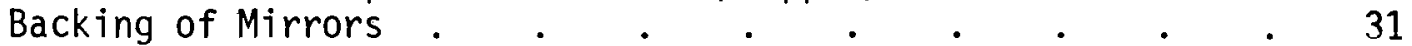

23. Mirror Sample Before Exposure to Acid Vapor . . . . . 32

24. Commercially Silvered Mirror after Scribing and Prior to Vapor Tests . . . . . . . . . $\quad . \quad 34$

25. Progressive Degradation of Mirror Samples

Exposed to $\mathrm{HCl}$ Vapors $. \quad . \quad . \quad . \quad . \quad . \quad . \quad . \quad 36$

26. Commercially Silvered Mirrors ..$\quad$. . . . . . . . . 37

27. Commercially Silvered Mirrors after HCl Vapor Test . . 38

28. Progressive Degradation of Mirror Samples

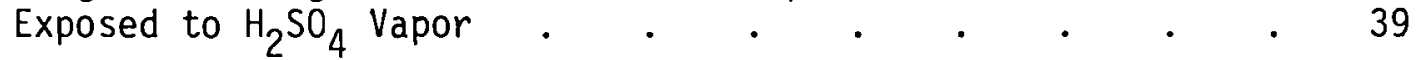

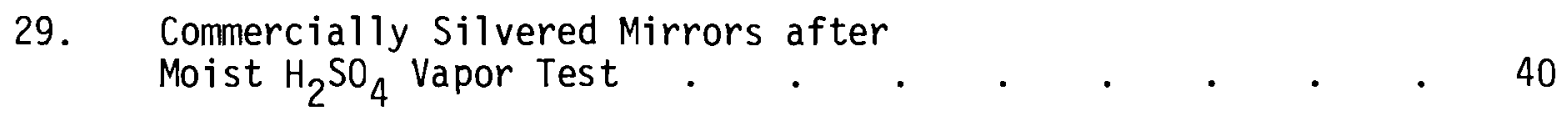

30. Progressive Degradation of Mirror Samples Exposed 42

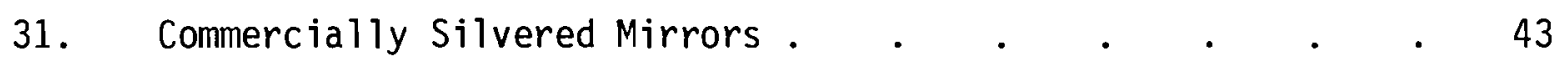

\begin{tabular}{l} 
32. Commercially Silvered Mirrors after \\
$\mathrm{HNO}_{3}$ Vapor Test \\
\hline
\end{tabular}

33. Commercially Silvered Mirrors after
$\mathrm{HNO}_{3}$ Vapor Test
$\mathrm{H}_{3}$ 


\section{LIST OF TABLES}

Table

1. Adhesives Screened . . . . . . . . . . . . 6

2. Average Tensile Pull Values in kpsi

for Four Separate Trial Runs . . . . . . . 20

3. Summary Comparison of Accelerated Tests on

Commercially Silvered Mirrors . . . . . . . . 33 

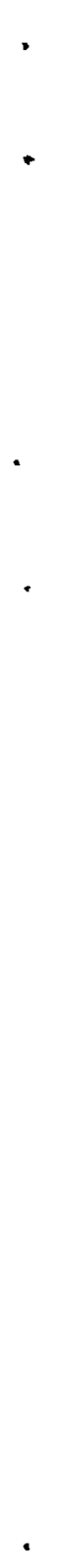

, 


\section{ADHESION TESTING}

The work on the adhesion testing reported here was motivated by the possibility that localized areas of poor adhesion at the silver to glass interface of second surface mirrors might be a precursor to delamination of the interface and subsequent corrosion of the reflective layer. Delamination at this interface has been observed in non-corroded areas of corroded heliostat mirrors and other mirrors subject to outdoor exposure. (1) Adhesion tests might also be used to indicate the quality of the glass surface preparation and metalization process considered by the mirror manufacturers to be crucial to good durability. If quantifiable, the adhesion tests could prove to be a useful quality assurance test for solar mirrors.

Toward this end, tensile pull tests were done on copper coated silvered mirrors to study the bond strength of the metal-to-glass interface. The purpose of the experiment was to see if it was possible to obtain a quantitative measurement of the adhesive strength of the chemically silvered mirror coatings, and to correlate the adhesive strength to overall mirror durability.

\section{Apparatus}

Tensile pull strength was measured using a Sebastian I Adherence Pull Tester. This instrument gives a quantitative measurement (in psi) of the bond strength of material interfaces. This is done by pulling a small aluminum test stud which is bonded to the coating surface to be tested (see Figure 1). The diameter of the surface of the studs used was $2.74 \mathrm{~mm}(0.108 \mathrm{in}$.$) .$

After bonding, the stud is inserted into a collar on top of the instrument. The stud is gripped by a flexible engagement mechanism. When the test is initiated the stud is pulled downward, forcing the material under test to contact the collar. If the stud is mounted with the shank normal to the plane of the material under test, the pulling force is also normal. A builtin LED display shows the load on the stud throughout the test. The load is calculated from the linear displacement of the test stud and the applied force. 


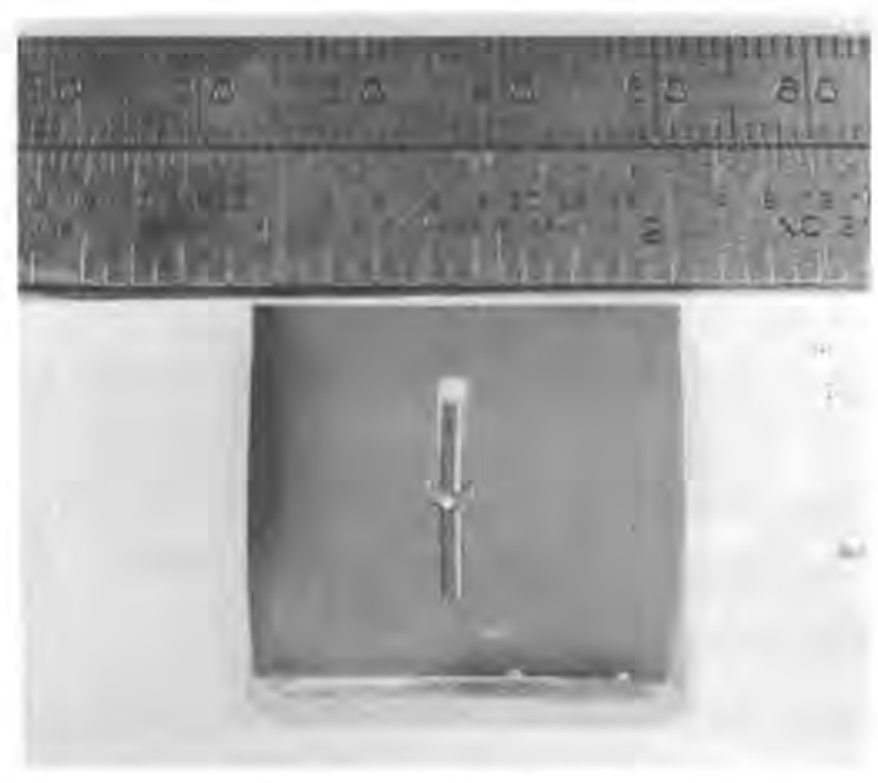

FIGURE 1. Mirror Sample with Stud Attached

The range of the instrument is $0-10,000$ psi. The accuracy of the test is reported by the manufacturer as \pm 1000 psi when epoxy-coated studs are used.

Examination of the stud and the film surface underneath the pulled stud identifies where separation occurred. Separation can occur within a layer of material (cohesive failure) and/or at the interface between two different material layers (adhesive failure). Thus the measurement obtained can be related to the yield strength of a particular interface (or combination of interfaces).

\section{Sample Preparation}

Mirror samples from four different manufacturers were tested. The manufacturers were identified with the letters C, G, B and FA or FT. Identical low iron soda-lime silicate float glass was used by all manufacturers. One surface of the glass was coated with a layer of silver ( $70.0 \mathrm{~nm}$ thick), followed by a layer of copper ( $30.0 \mathrm{~nm}$ thick) and a layer of paint ( $0.025 \mathrm{~mm}$ thick). During the production of float glass, one surface of the glass floats on a molten tin bath. Generally the glass surface not exposed to the $t$ in bath is the surface that is silvered. Manufacturer $F$ provided mirror 
samples that had been silvered on both sides of the glass. The glass silvered on the side in contact with the molten tin bath were labeled FT. Mirrors marked FA were silvered on the glass surface not in contact with the tin bath.

Mirror samples were cut into one-by-one inch squares for testing. All samples were cleaned and degreased by rinsing successively with $1,1,1$ trichloroethane, acetone, methyl alcohol and ethyl alcohol and then thoroughly dried prior to attaching the stud.

Stud Bonding

The method of attaching the test studs to the mirror samples is critical to the validity and interpretation of the adherence data. Epoxy coated studs were provided by the Sebastian I manufacturer. The epoxy required heat curing at $125^{\circ} \mathrm{C}$ for 2 hours. This temperature exposure caused slight visual hazing of the silver layer on the mirror samples which might be attributed to agglomeration of the silver. Interestingly, little or no hazing was visible in the silver region directly beneath the stud, while the effect was enhanced in the area around and directly adjacent to the stud (see Figure 2). An attempt was made to cure the epoxy at $100^{\circ} \mathrm{C}$ for 4 hours, but again the silver layer showed slight hazing. Therefore, the use of the epoxy-coated studs was discontinued. Test studs without the epoxy coating are available, but a suitable adhesive is required.

The selection of an adhesive was predicated on the following four criteria:

1) it must be rigid setting

2) it must not require elevated cure temperatures

3) it must provide a good enough bond between the aluminum stud and the painted mirror back so that neither the glue-to-stud or glueto-paint bond fails

4) it must be strong enough so that adhesive failure of the mirror coating materials precedes cohesive failure of the adhesive. 


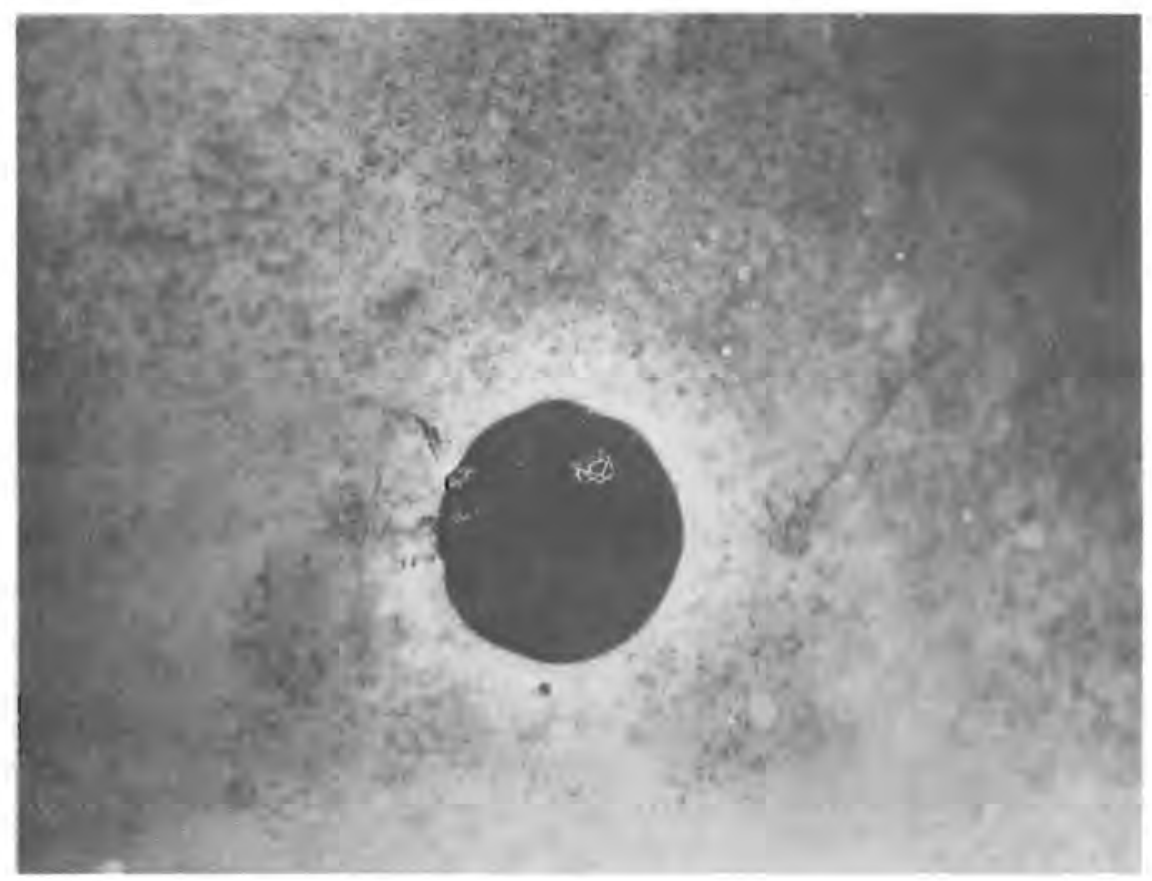

FIGURE 2. Reflected Light Photograph of the Area Surrounding and Under (dark area) the Stud after Heat Cure. The light area appears visually similar to agglomerated silver.

Requirements 3 and 4 proved most difficult to meet. Problems were encountered in trying to find an adhesive that would adhere strongly to the aluminum test stud. Oxidation of the aluminum, irregular bonding surface of the stud and cleanliness of the stud could have contributed to the poor bonding. Before applying the adhesive, the stud heads were abraded with a wire brush to remove the surface oxidation layer and provide an even bonding surface. The studs were then cleaned and degreased following the same procedure used on the mirror samples.

An adhesive that would bond strongly to the painted surface of the mirror could not be found due in part to the cohesive failure of the paint. 
Therefore, for the majority of the testing reported here, the paint layer was stripped off the mirror and the test studs were bonded directly to the copper layer. Stripping was done using a 2:1 solution of methylene chloride and methyl alcohol. The mirror samples were immersed in this solution before cleaning. Generally, the entire paint layer lifted off intact within minutes. But occasionally small areas of paint would remain. For one mirror type $(G)$, it was particularly difficult to remove the paint. Some of the paint could not be rubbed off without removing or scratching the copper layer.

A number of commercial adhesives were screened (see Table 1). Only the two-part epoxies were successful in meeting our criteria. Contrary to expectations, the cyanoacrylates did not prove suitable. A maximum bond strength of 2500 psi was obtained using Eastman 910, but this adhesive did not give consistently high readings. The studs often fell off before the samples could be tested. None of the silver layer was ever pulled off the mirrors using Eastman 910 either by itself or using alternate techniques recommended by the manufacturer.

Figure 3 shows the two-part epoxies that adhered well enough so that some of the silver layer was pulled off the mirror sample along with the test stud (at least some of the time). This figure also shows the range of bond strengths recorded for each of the different epoxies during preliminary testing. Tra-Bond 2112 provided the strongest bond with maximum yield strength in excess of 7000 psi. It gave consistently strong bonds and pulled silver off the mirror samples most of the time. This was the adhesive used for the remainder of the tensile pull tests. Tra-Bond 2112 fully cured at room temperature in 72 hours. Faster curing was possible at $65^{\circ} \mathrm{C}$. No visible silver agglomeration occurred when samples were baked at $65^{\circ} \mathrm{C}$ for 2 hours, so this baking step was incorporated into the standard cure cycle.

\section{Experimental Results}

The results of the adhesion tests using the above method were disapointing. There were no conclusive or even consistent quantitative results. However, some qualitative observations are worth noting. 
TABLE 1. Adhesives Screened

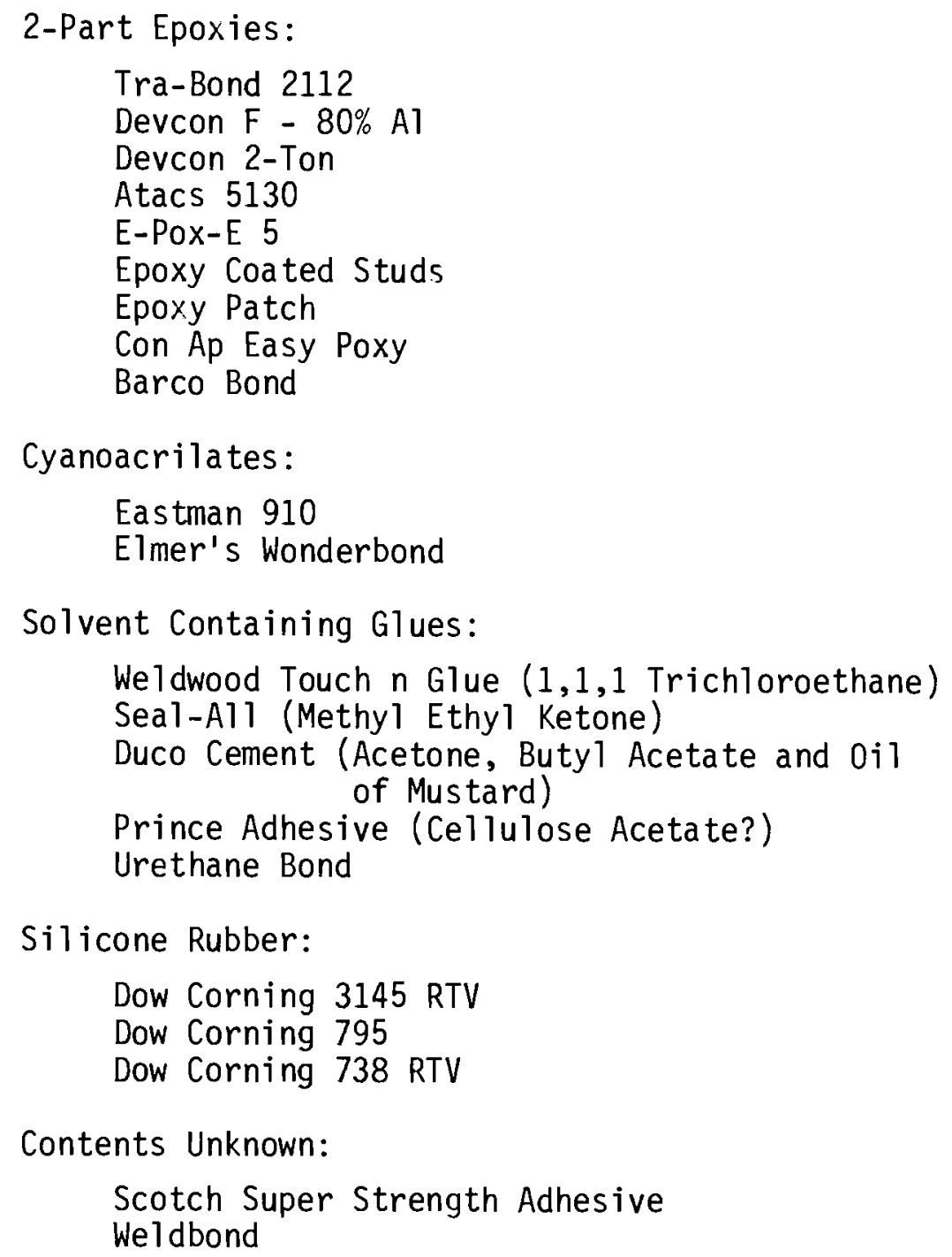

While the pull test was in progress, an interesting phenomenon was observed on nearly all the samples. Looking through the glass layer, a ring appeared in the silver layer around the stud head at some point during the test. The silver layer appeared to be pulling away from the glass in a welldefined ring well outside the stud diameter or any excess adhesive. Sometimes only a segment of the ring was visible. From sample to sample, this phenomena 
GLUE TYPE:

TRA-BOND 2112

DEVCON F

DEVCON 2-TON

EPOXY COATED STUDS

ATACS 5130

E-POX-E 5

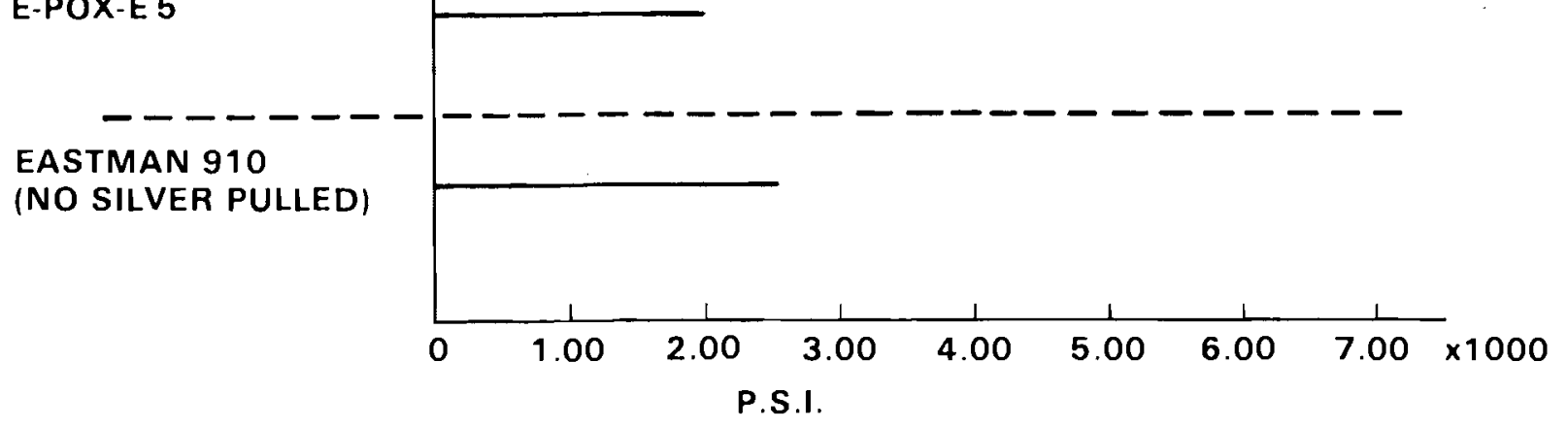

FIGURE 3. Adhesive Bond Strength Ranges (Preliminary Tests)

would appear at different times during the test. It sometimes appeared very early in the test, but other times it did not appear until just before the stud was pulled off.

The time of the ring's appearance during the test seemed random. No discernible patterns or correlations were observed. Upon removal of the stud, the ring was often still present. But occasionally, especially in the cases where no silver was pulled from under the stud, the ring did not remain upon completion of the test. Figure 4 shows a close view of the area surrounding the stud location after the pul1 test. The ring beyond the contact area of the stud is clearly visible. This could be caused by shear forces generated in the silver film during the tensile pull test. 


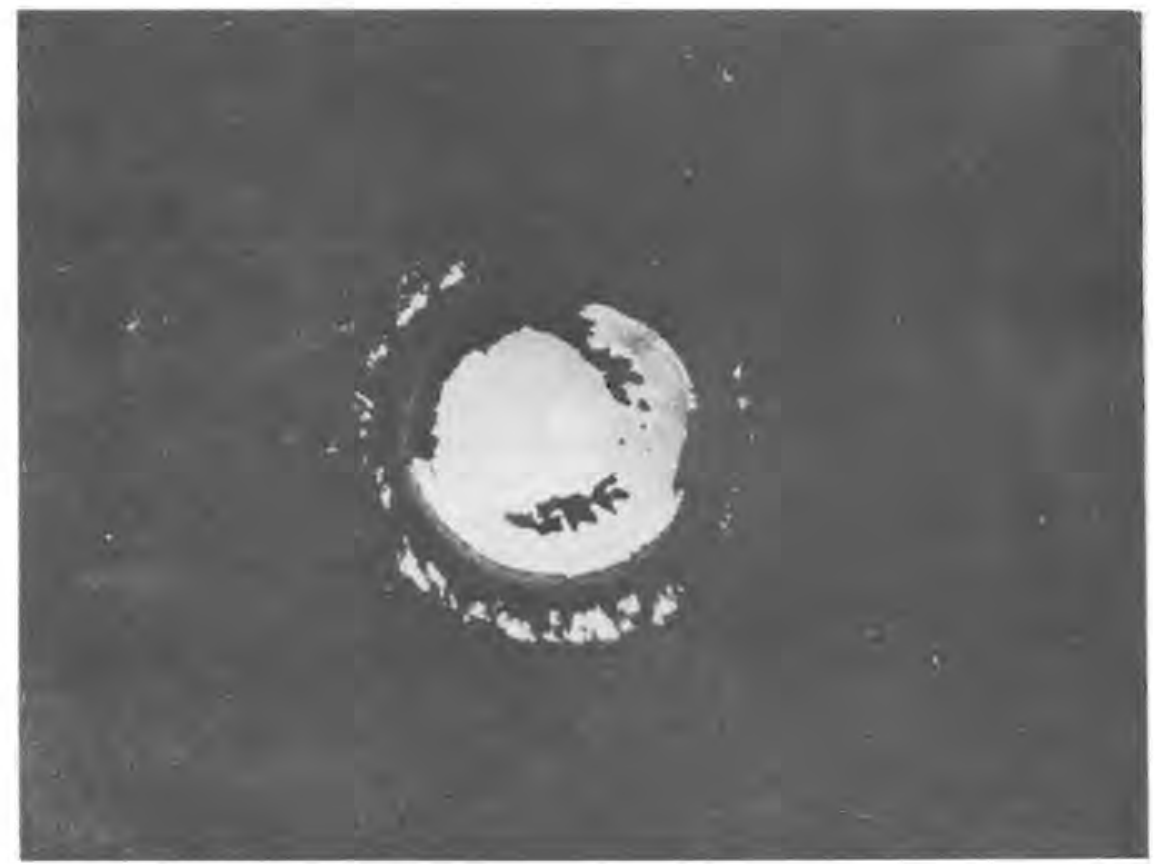

FIGURE 4. Transmitted Light Photograph of Area Surrounding the Stud after Tensile Pull Test. The ring around the central disk was not under the stud.

There were four observed regions of failure in the mirror samples tested. These were at the silver/glass interface, the adhesive/stud interface, the adhesive/copper interface, and cohesive failure within the adhesive. A combination of two or more failure modes was generally found on any given sample. Partial separation of the silver-to-glass interface predominated. There was no obvious separation between the copper layer and the silver layer.

In nearly all the mirror samples tested, at least some of the silver layer was removed as shown in Figure 5. For the B \& C mirrors, some silver was pulled on about $90 \%$ of the samples tested. For the FA and FT mirrors, silver was pulled $100 \%$ of the time. However, the silver layer was pulled on only $16 \%$ of the G samples tested.

Figure 6 shows the quantitative results of the tensile pull test for each mirror type. This chart shows the average tensile stress in psi (normalized to the stud area of 0.009 square inches) required to pull the studs 


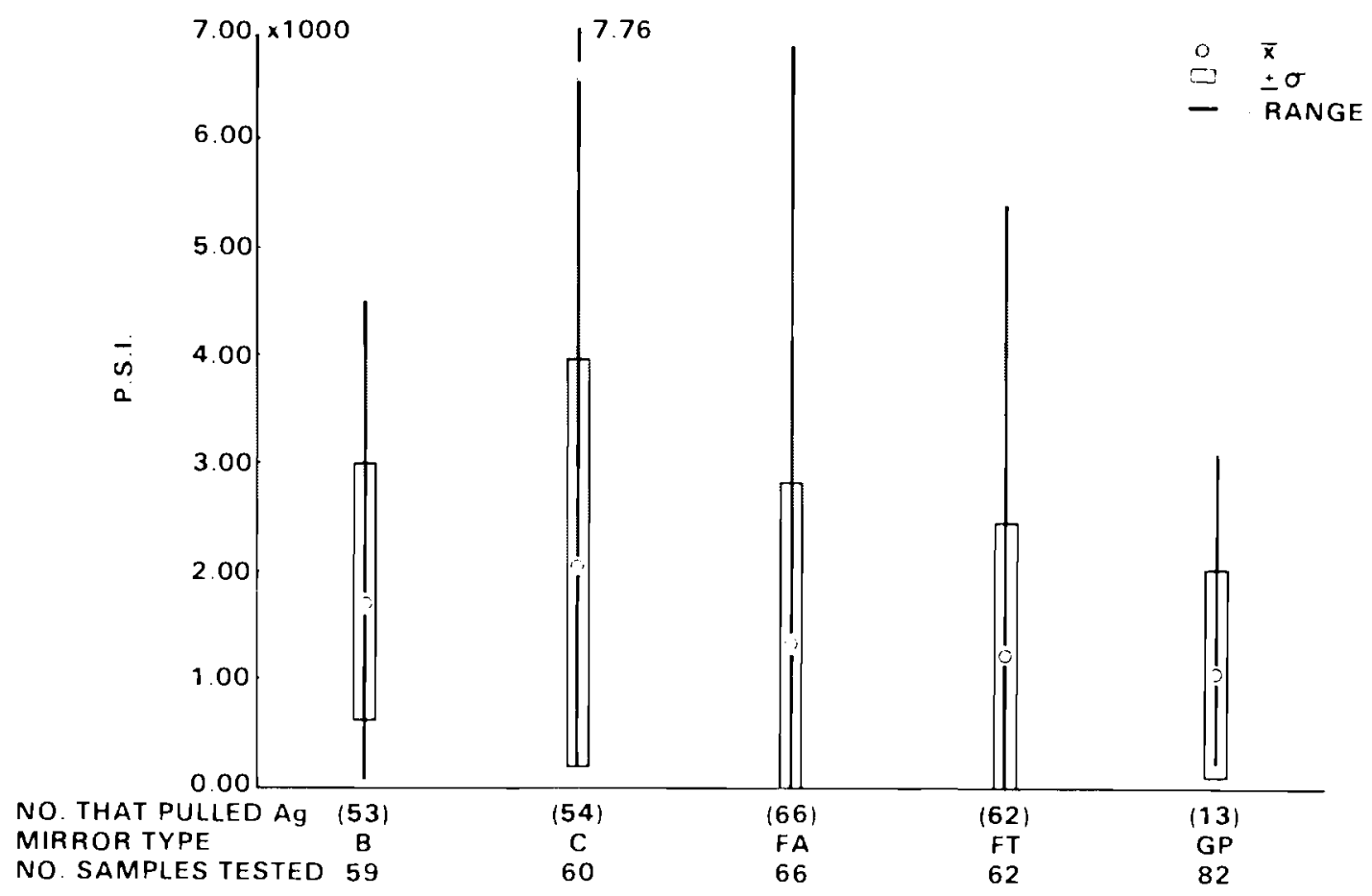

FIGURE 5. Percent of Mirror Samples Tested that had Silver Backing Pulled

\section{MIRROR TYPE}

B

C

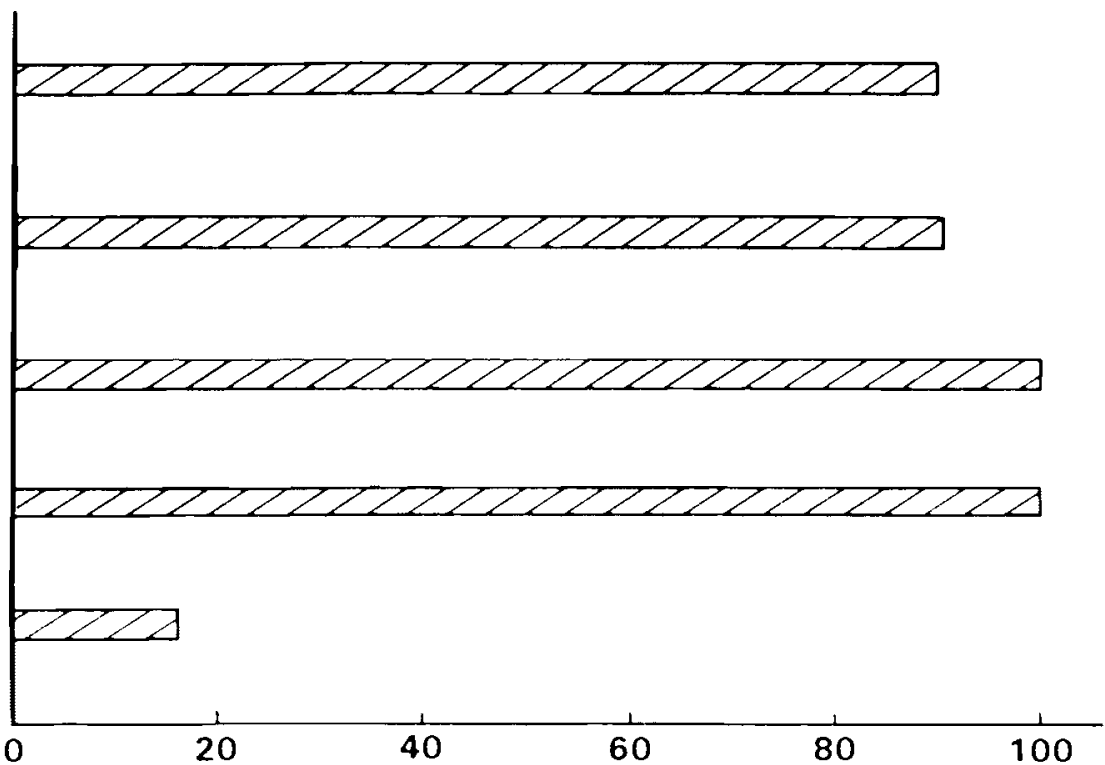

of Samples Tested that hac Silver Pulleci

FIGURE 6. Tensile Pu11 Test Results for Cu-Ag Backed Mirror Samples 
off the mirrors. The rectangle indicates the standard deviation $( \pm \sigma)$ of the measurements and the solid line shows the range of readings that resulted in some silver removal. The mirror type, the total number of mirror samples tested and the number of samples tested that had any silver pulled are also indicated. The data for the samples that had no silver pulled are not reflected in these plots.

The range of force needed to remove the stud is large as is the standard deviation. For example, some silver was pulled off the $C$ mirror samples along with the studs for yield strengths ranging from 250 psi to nearly 8000 psi. The other mirror types exhibited similar results. The small differences in average yield strength for the different mirror types are insignificant in light of the large, overlapping standard deviations.

From sample to sample, widely varying amounts of the silver layer were pulled from under and around the stud. In an attempt to compensate for the varying amounts of silver pulled, the data were normalized to the area of silver removed. The area removed was measured by imaging the transparent regions of a sample (where the silver layer was removed) onto a CCD camera. The light versus dark pixels were counted and compared with calibrated standards. The estimated accuracy of measuring surface area in this manner is better than $5 \%$.

Plots of yield load versus fractional area of silver removed (as compared to the total area under the test stud) are shown in Figures 7-11. The means and standard deviations of the measurements are indicated. These plots include yield load measurements for all test samples, regardless of whether any silver was removed. The quantitative yield data are not much different from the data shown in previous plots (see Figure 6). An exception is the $G$ sample results shown in Figure 11 . For all mirror types except $G$, the average yield load was about $5 \mathrm{~kg}$. The $\mathrm{G}$ samples showed an average yield load in excess of $10 \mathrm{~kg}$. The difference can be attributed to the large number of GP samples having high yield load values but resulting in no silver pulled. 


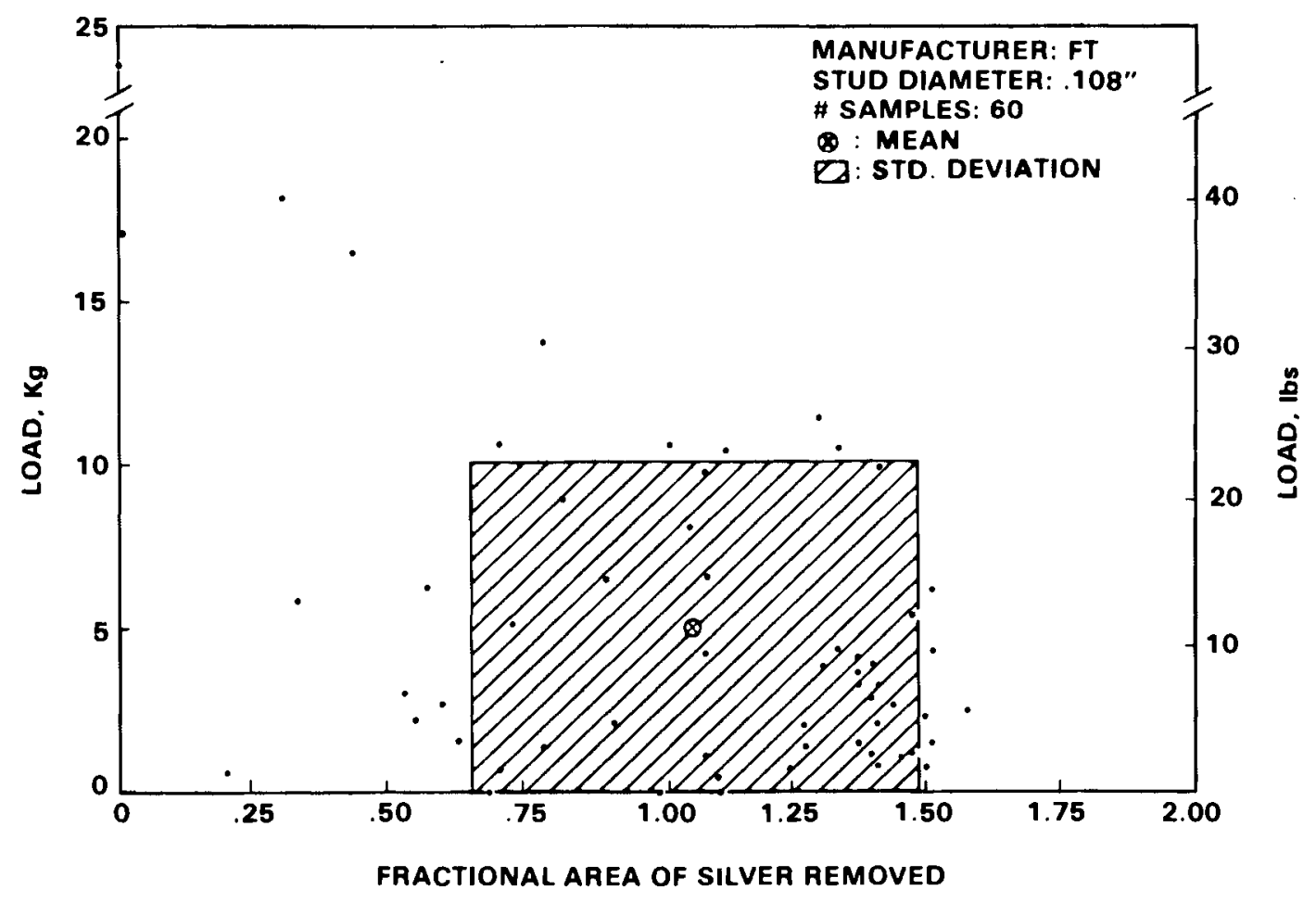

FIGURE 7. Area Normalized Yield Load for FT Samples

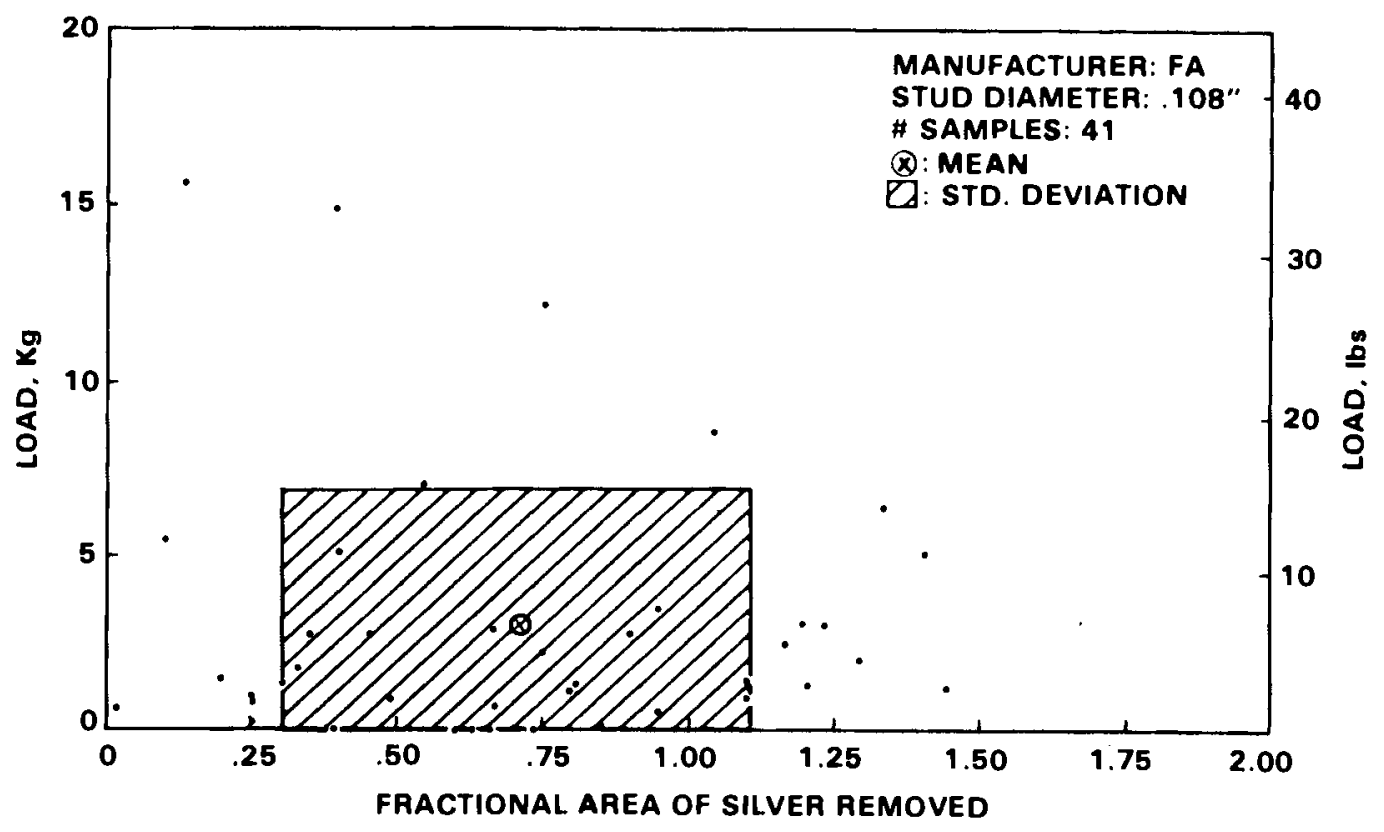

FIGURE 8. Area Normalized Yield Load for FA Samples 


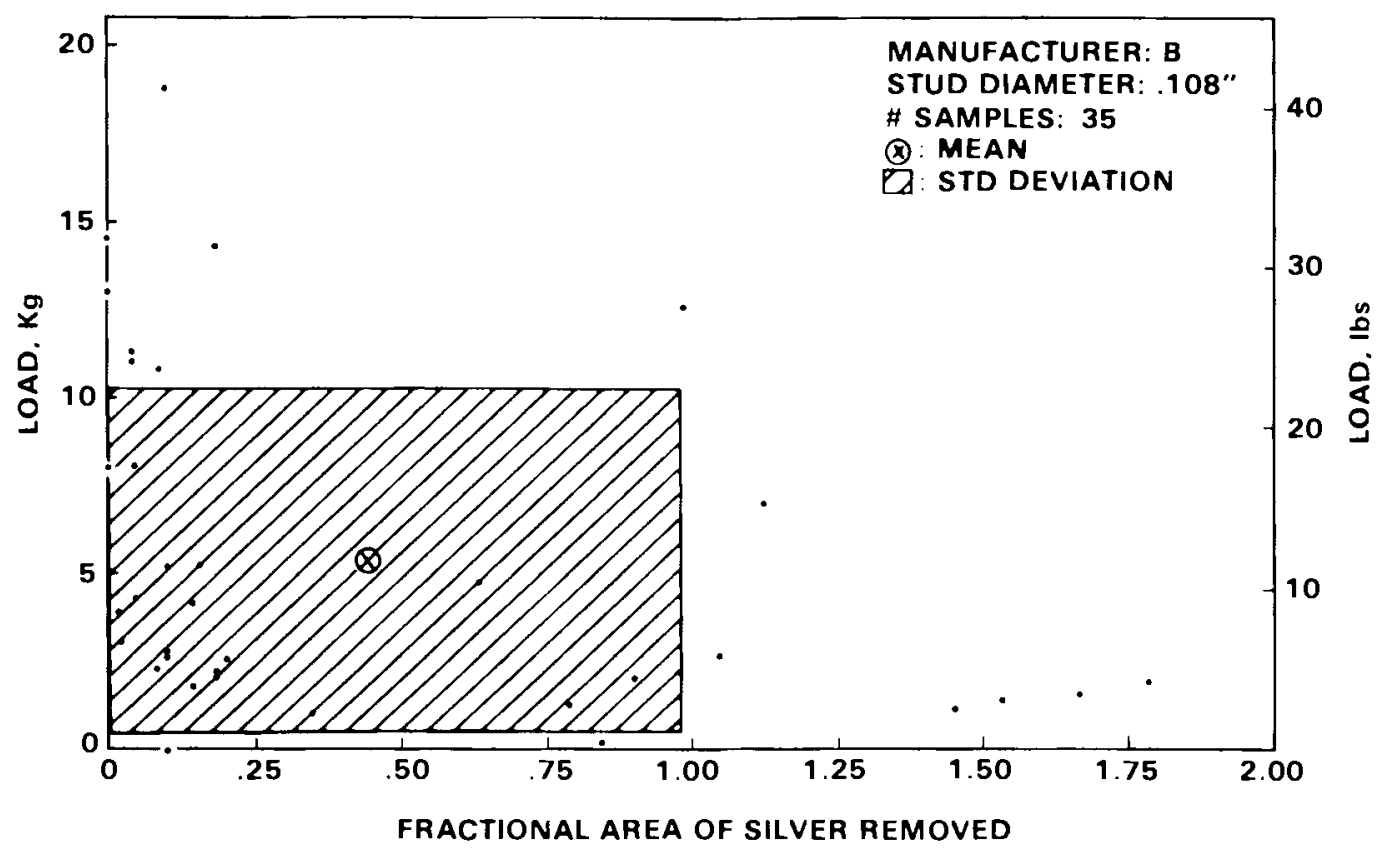

FIGURE 9. Area Normalized Yield Load for B Samples

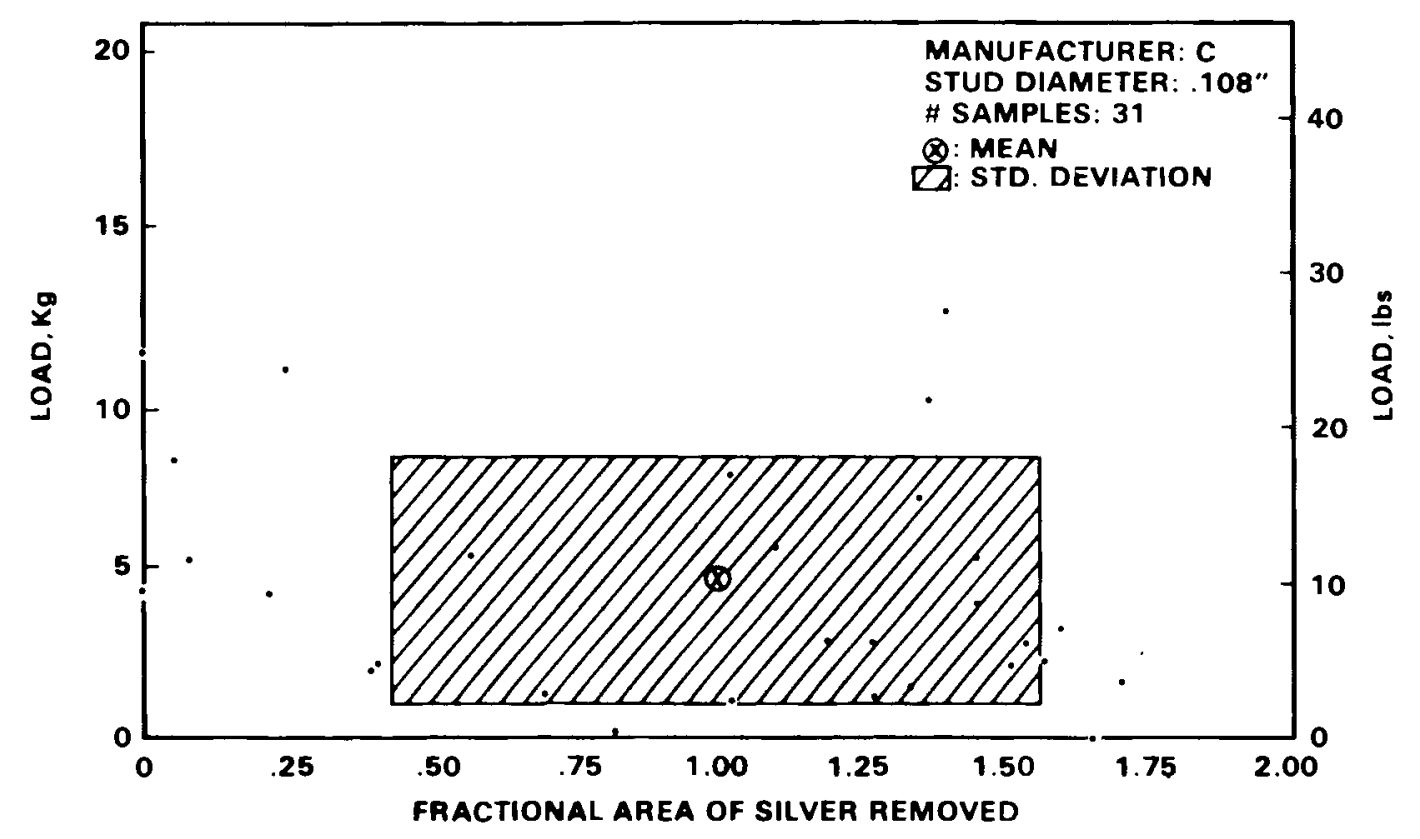

FIGURE 10. Area Normalized Yield Load for C Samples 


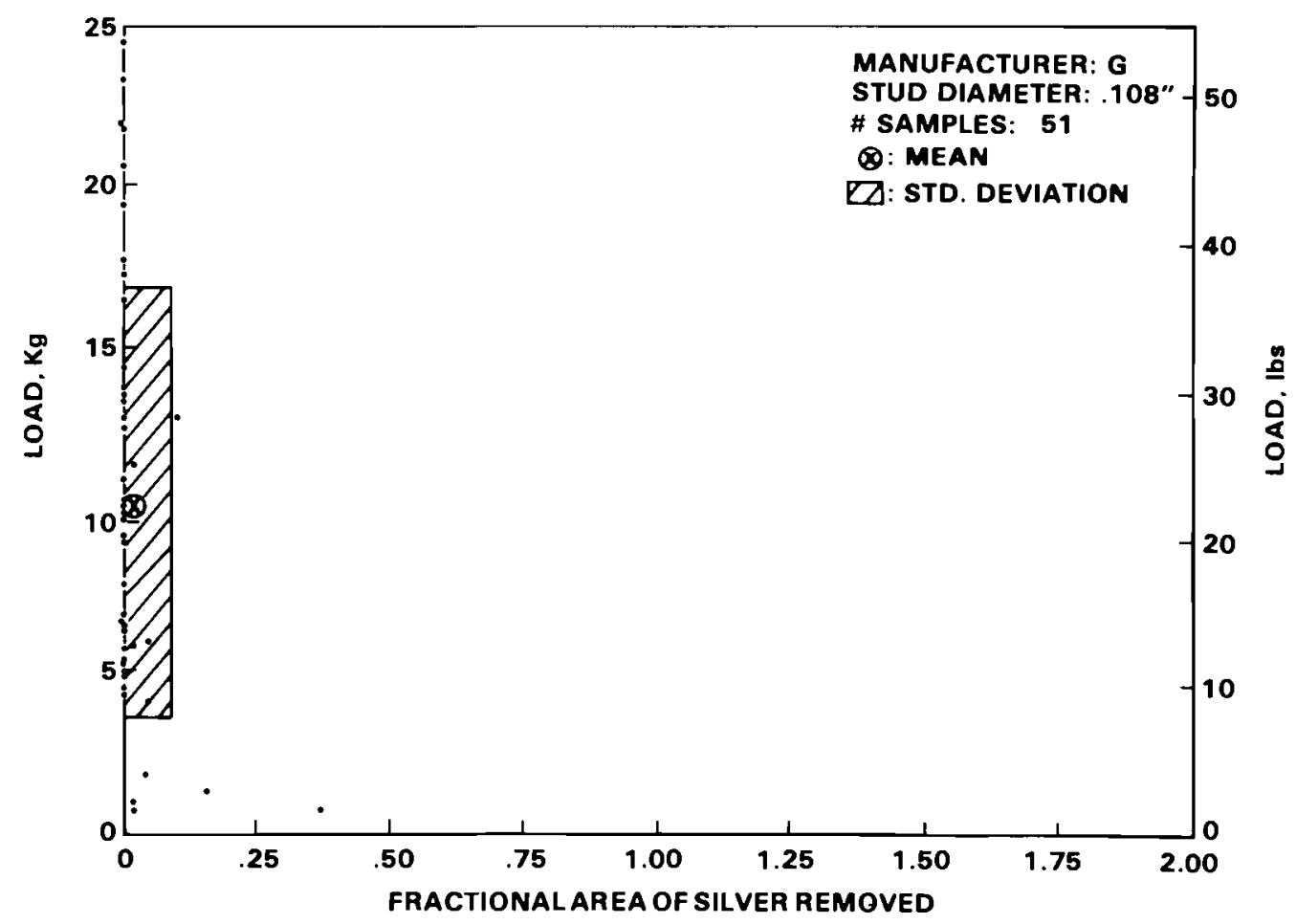

FIGURE 11. Area Normalized Yield Load for G Samples

Al though these results indicate a dramatic shift in the mean value for the yield load for one mirror manufacturer, the large error bars associated with the data severely 1 imit its persuasiveness as a comparison measurement. The comparative quantitative information is of little value. Sti11, some significance might be attached to the differences in fractional area of silver removed for the different mirror types. Some of the differences here are meaningful in spite of the large standard deviations. Very little silver was pulled from the G mirrors. A large amount of silver, of ten exceeding the total area under the stud, was pulled from the $C$ and FT mirrors. Moderate amounts of silver were pulled from the $B$ and FA mirrors.

Additional data was compiled to determine if differences could be seen between mirrors that were silvered on the sides of the float glass in contact with the molten tin bath versus the non-contact side. Plots of the yield load per fractional area of silver removed, versus fractional area of silver removed were done for the mirror samples FA and FT. The results are plotted 
in Figures 12 and 13. The inner squares show the statistics when measurements outside $+3 \sigma$ from the mean are considered outliers and are excluded. With outliers excluded, yield loads are indistinguishable for the two groups, but more silver is pulled on the mirrors silvered on the side of the glass in contact with the molten tin (FT).

Validity of the Test

The large amount of scatter in the data and the appearance of visual non-uniformities in the region of the bonded stud as described previously are two reasons to question the validity of this type of tensile pull test as being truly representative of the interface adhesion. Questions of primary concern are to what extent the sample preparation (paint stripping, cleaning, bonding and curing) affect the metal/glass interface under study. One measurement technique used in a preliminary attempt to explore these questions was ellipsometry.

Ellipsometry is a non-destructive optical technique that is very sensitive to small changes in the optical properties of materials and interfaces. It is based on the polarization sensitive differences in the reflection of a light beam at a material interface. Light polarized parallel and perpendicular to the plane of incidence will generally experience changes in both phase and amplitude upon reflection. Ellipsometry is a method of accurately measuring these relative changes in the input and output beam ${ }^{(1)}$ which are sensitive to small changes in the optical medium.

Ellipsometry data can be used to deduce the optical properties of a surface if an accurate theoretical model of the surface is available. In this preliminary study, no attempt was made to deduce specific optical properties from the data, so none of the analysis is model-dependent. The only concern was whether or not any changes were occurring at the metal/glass interface during sample preparation. Ellipsometry data can be used to monitor the effects of an experimental procedure on an interface by taking a series of measurements before and after critical points in the procedure. The data 


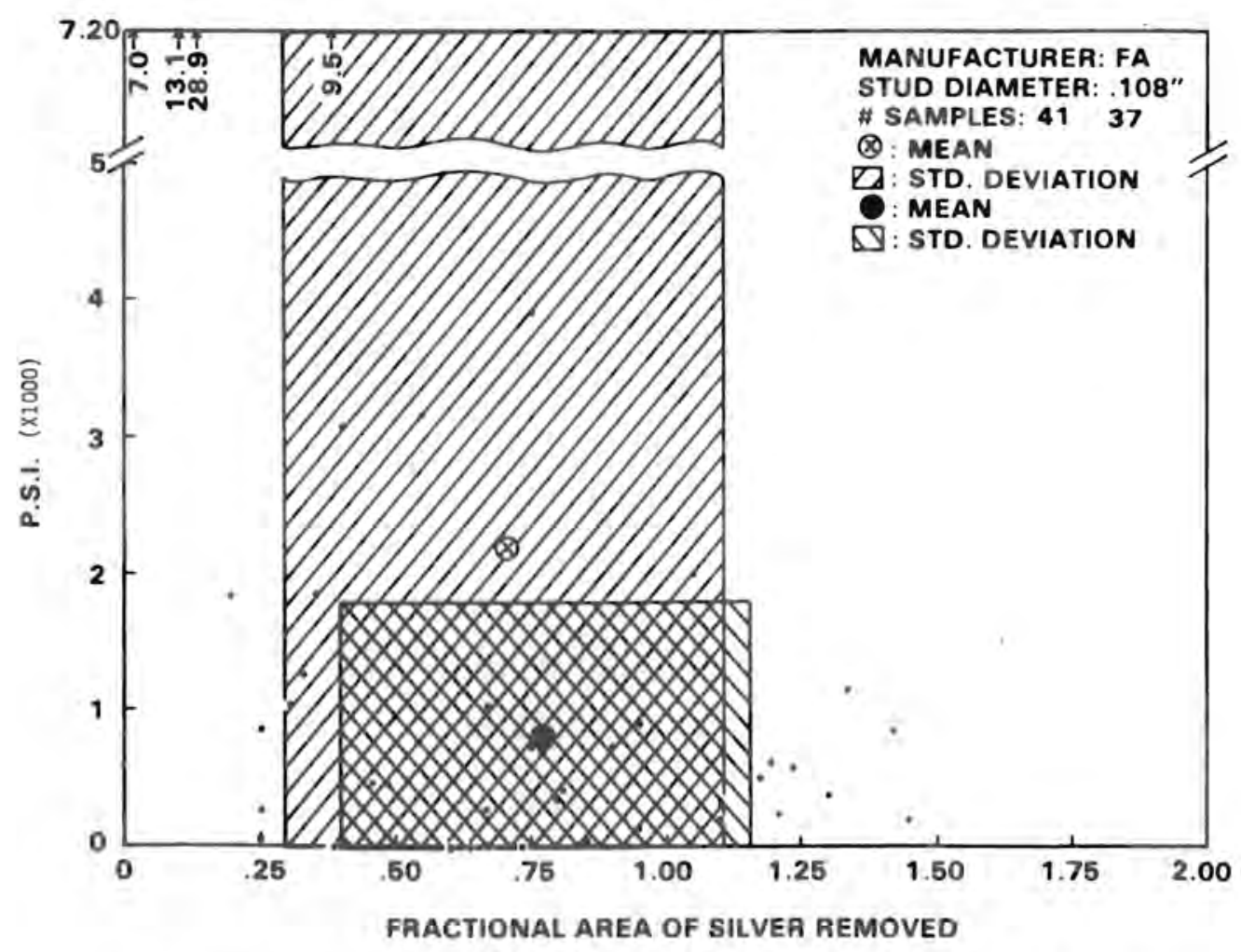

FIGURE 12. Area Normatized Yield Load for FA Samples

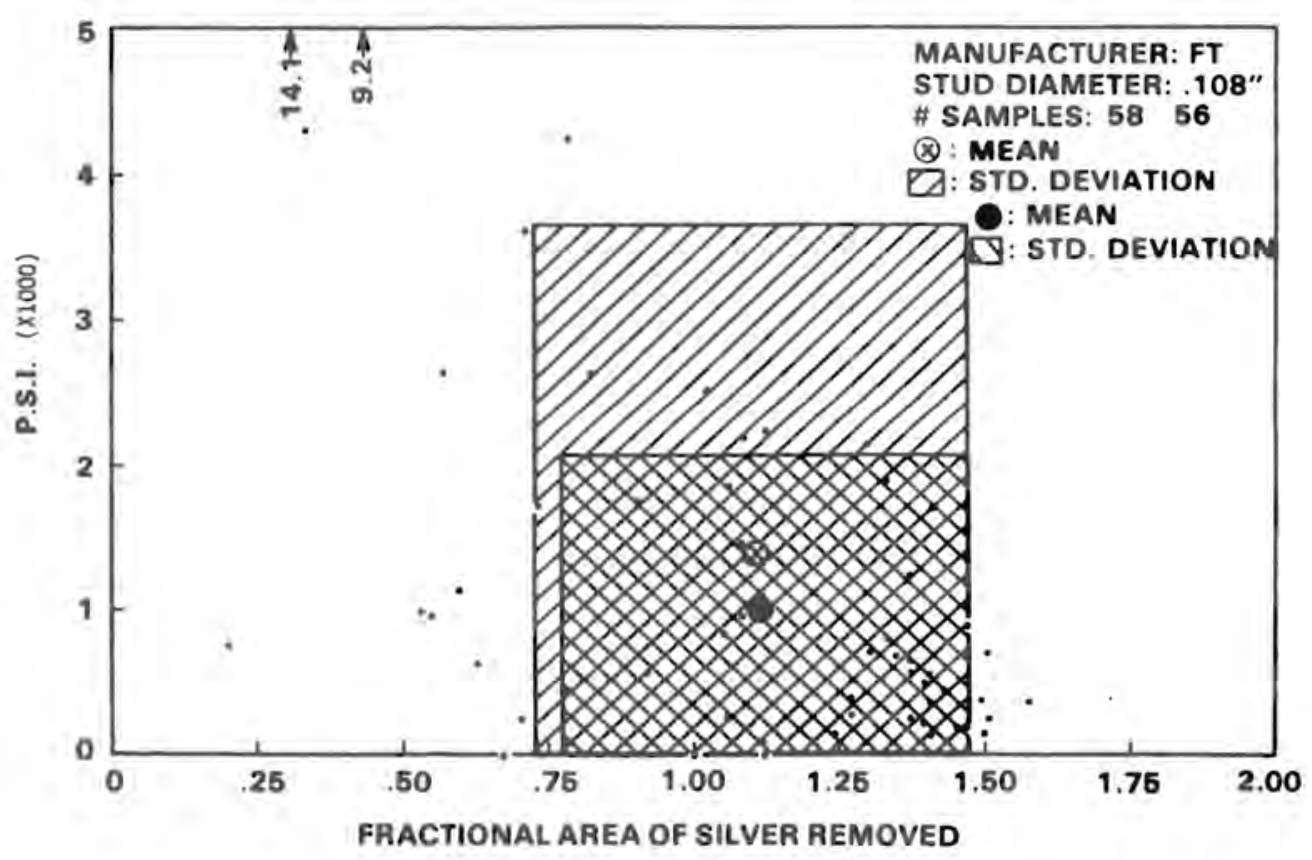

FIGURE 13. Area Normalized Yield Load for FT Samples 
is then analyzed to determine if there are any relative changes in the measurements associated with the various processing procedures. The ellipsometry measurements themselves are straightforward and correspond to a real configuration of the sample. Therefore, a significant change in the ellipsometry measurements corresponds to a change in the sample.

Two ellipsometric parameters are usually measured. These parameters are designated $\psi$ and $\Delta$. $\psi$ is defined as the arctangent of the ratio of the $s$ and p polarized reflection coefficients

$$
\psi=\tan ^{-1}\left|\frac{r_{p}}{r_{s}}\right| .
$$

Thus $\psi$ is related to the relative amplitude of the reflected wave. $\Delta$ is the difference between the relative change in the phase of the reflected $p$ and $s$ polarized wave.

$$
\Delta=\delta_{r p}-\delta_{r s}
$$

For each series of measurements described below, ellipsometry measurements were taken in five places on each mirror sample. One measurement was taken in the center of each sample, corresponding to the spot where the stud would be bonded. Four other measurements were taken $4.4 \mathrm{~mm}$ ( $0.175 \mathrm{in}$.) above, below, to the right and to the left of the center position. The measurements were taken with the light beam passing through the glass layer and reflecting off the silver/glass interface. Any inhomogeneities in the glass and its refractive index could contribute to changes in the measurements that would not be indicative of changes at the metal/glass interface. Therefore, care was taken to insure that the mirror samples were aligned the same way for each set of measurements and that the measurements were taken in the same five locations on each sample.

Initial measurements were taken after the samples were cut into one-inch squares but before any cleaning or degreasing was done. The samples were then prepared for the tensile pull test using the standard procedure. Ellipsometry measurements were re-taken after the mirrors were stripped, 
after the cleaning/degreasing process, after the studs were bonded to the mirrors (using Tra-Bond 2112) and after heat curing $\left(2 \mathrm{hr}\right.$ at $65^{\circ} \mathrm{C}$ ). A control sample that was left untreated was remeasured throughout the experiment along with the other samples. This provided a reference baseline for determining the significance of a measurement change.

No significant changes were found in either the $\psi$ or $\Delta$ measurements after the stripping, cleaning or bonding steps. Very significant changes occurred in the $\Delta$ readings taken after the heat cure. The measurement in the center of the mirror, underneath the stud, showed the most drastic change. The other four measurements also showed definite changes, but of much less magnitude than the center measurement. The center measurement of $\Delta$ consistently decreased in magnitude, while the changes at the other four positions were scattered as shown in Figure 14. Measurements of the control sample remained very constant throughout the experiment.

Another experiment was performed using the epoxy-coated studs supplied by the instrument manufacturer. The mirrors were heat cured for $2 \mathrm{hr}$ at $125^{\circ} \mathrm{C}$ as per manufacturer's recommendation. Changes in the measurements after the heat cure were exactly analogous to that of the mirrors bonded with Tra-Bond adhesive. Again, the measurement in the center of the sample showed the most severe changes.

A third experiment was then done using Tra-Bond 2112 as the adhesive, but without the heat cure. The samples were left for three days at room temperature to cure. Changes were evident after the curing cycle, but they were all random in nature (see Figure 14). In particular, the center measurement did not exhibit the drastic change that was evident after the elevated heat cure.

Tensile pull measurements were done using Tra-Bond 2112 as the adhesive with half the samples cured at $65^{\circ} \mathrm{C}$ for $2 \mathrm{hr}$ and the other half left to cure for 3 days at room temperature. Significant differences in tensile pull measurements were found. Average measurements for the mirrors cured at room 


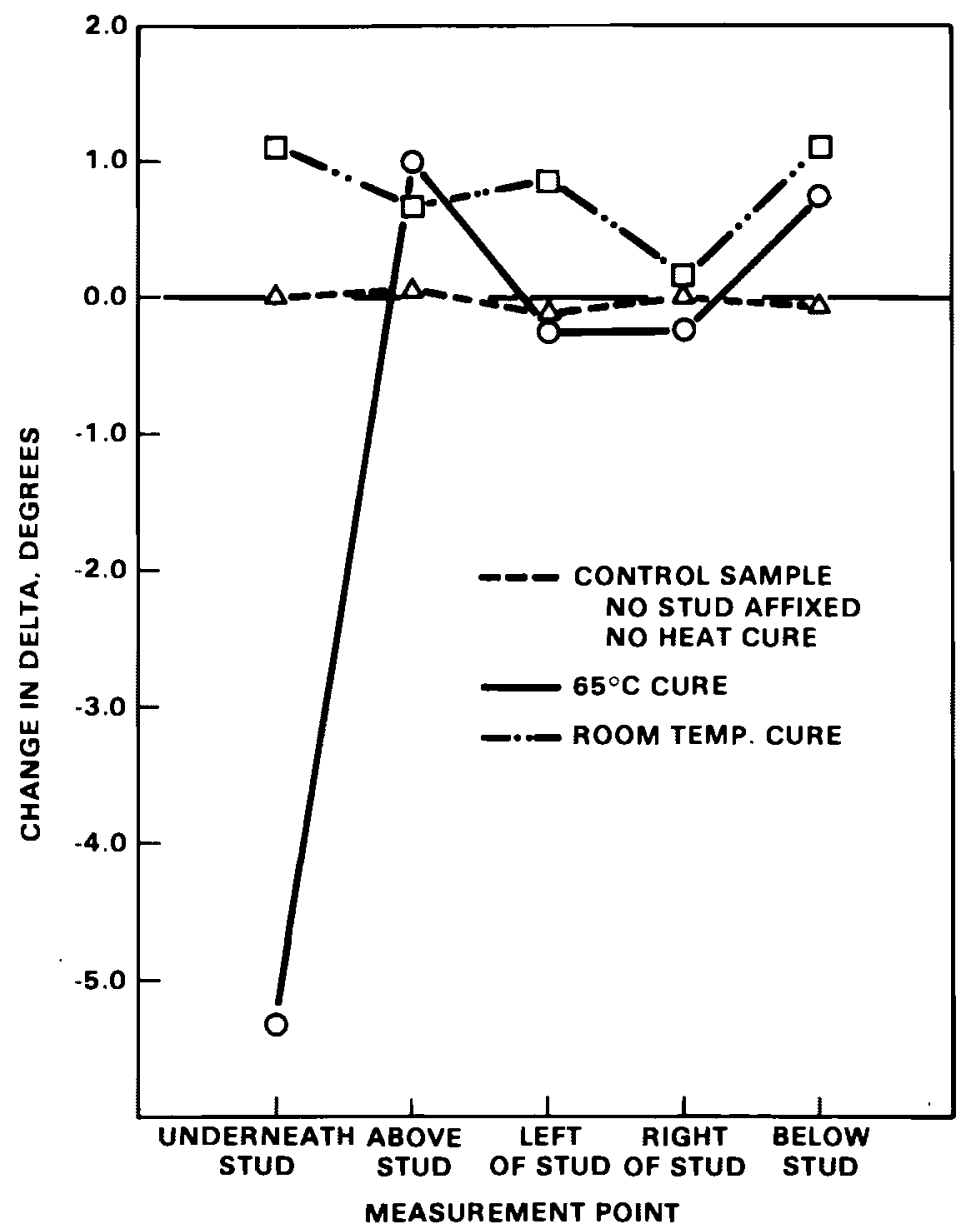

FIGURE 14. Effect of Elevated Temperature Cure on Mirror Samples (Typical Ellipsometric Results)

temperature were $0.63 \pm 0.57$ psi while the results for the mirrors cured at $65^{\circ} \mathrm{C}$ were $2.12 \pm 1.40$ psi. Failure modes looked consistent on all the samples, but more silver was pulled on those cured at room temperature.

It is evident that the adhesive cure cycle does induce changes at the metal/glass interface. The changes appear to be more drastic when elevated temperature cures are used. Resources were not available to identify the specific nature of the changes at the interface. As a result, the effect of the changes on tensile pull measurements is difficult to predict. 
Recall that the original purpose of this series of experiments was to obtain quantitative measurements of the adhesive strength of mirror coatings to glass substrates using the tensile pull test. The goal was to determine if these measurements could be used to characterize and differentiate between mirrors. The Sebastian I Adherence Pull Tester did not appear to provide a simple and direct method of obtaining quantitative adhesive strength measurements between the silver and glass interface. Many problems were encountered, both practical and theoretical, which served to severely limit the value of the data and the interpretation.

Adhesive problems dominated nearly all aspects of the experiment. The best adhesive found did not provide satisfactory bonding to all surfaces. Inconsistent results in tensile pull measurements from one trial to another may have been due in part to the effect of temperature and humidity on the curing of the adhesive. (3) In particular, high humidity during the bonding and curing cycle seemed to have an adverse effect on the bond strengths mea sured.

It was absolutely essential that the studs be bonded perpendicular to the surface of the mirror. $(4,7)$ It was difficult to insure that these perpendicular bonds were obtained and maintained throughout the bonding and curing cycle. Non-perpendicular bonds could distort the tensile nature of the pull test stresses. Variations in the thickness of the adhesive layer could result in non-uniform stress distribution during the pull test. (4)

Ellipsometry measurements indicate that the bonding and curing cycle disturb the metal/glass interface. The effect of this on the adhesion strength measurements is not known.

The fact that a combination of failure modes was generally present on any given sample was also disturbing. Some researchers maintain that peel stresses and glue fracture predominate after the weakest area of the film is detached. (5) Therefore it may not be true that all the failure modes on a given sample are due to the measured tensile pull stress. It was not possible to determine which failure mode represented the weakest bond on a sample. Stresses at the metal/glass interface were most likely not pure tensile 
anyway, since an applied tensile stress will induce a shear stress according to the Poisson ratio for that material. $(5,7)$

The absolute numerical results of this experiment were of little value in characterizing mirror samples. Not only were standard deviations and ranges very large, but from trial to trial there were large variations in the mean values, as illustrated in Table 2. Correcting the yield stress measurements (which were machine normalized to the area of the stud head) to the actual area of material removed did not improve the results significantly. A persuasive explanation was not found for the widely varying areas of metal removed. The large scatter in the measurements might accurately reflect the nature of the metal/glass bond. This cannot be stated conclusively since other sources indicate that wide variations in measurements are common in thin film adhesion tests. (6) Furthermore, measurements of studs bonded directly to glass (using Tra-Bond 2112 and a $2-\mathrm{hr}, 65^{\circ} \mathrm{C}$ cure) showed scatter similar to that of the mirror measurements.

TABLE 2. Average Tensile Pull Values in kpsi for Four Separate Trial Runs

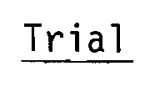

1

2

3

4

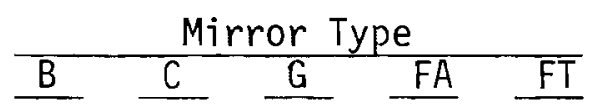

$2.7 \quad 3.6$

$\begin{array}{lll}0.3 & 0.2 & 0.4\end{array}$

$1.3 \quad 1.9$

0.2

$\begin{array}{lll}1.1 & 0.8 & 1.2\end{array}$

2.7

0.3

$1.1 \quad 1.5$

\section{Conclusion}

It does not seem possible at this time to conclusively characterize mirrors on the basis of quantitative tensile pull measurements. The many problems and questions involved make convincing analysis of the data difficult. The large scatter and inconsistencies in the data make even relative comparisons between different mirror manufacturers of limited usefulness. 


\section{CHEMICAL VAPOR TESTS}

Without a thorough understanding of the mechanisms involved in the degradation of field service solar mirrors, it is unlikely that the appropriate stresses can be applied to simulate the phenomena in an accelerated test. If accelerated testing is required, the best that can be done under the circumstances is apply tests that attack suspected weakness and compare the results with naturally aged specimens of the same materials. This is the purpose of the chemical vapor tests reported here. It is likely that porosity of the silver layer backing (copper, paint, etc.) may greatly affect the lifetime of the mirror. Since the observed natural degradation appears to spread from localized areas, it is also likely that the mobility of certain chemical species at the mirror interfaces may also play a significant role. Unfortunately, the active species have not been convincingly identified from a large group of potential actors. Therefore a variety of chemical vapor tests were conducted for comparative evaluation.

The accelerated degradation tests were performed on manufactured mirror samples in an effort to discriminate between the mirrors and try to predict their overa 11 performance. Mirror samples from four different manufacturers were subjected to boiling water, salt spray and acid vapor tests. All mirrors were prepared on identical substrates.

For these tests, the glass surfaces of the mirror samples were cleaned by successive rinses with trichloroethane, acetone, methanol and deionized water. The painted back surface of the mirror was rinsed with methanol and deionized water only, since the trichloroethane and acetone softened the paint. A grid pattern was then scribed in the back of the mirror through the paint, copper and silver layers to the glass. The samples were then rinsed again with deionized water and left to dry before being tested. Mirrors from four different manufacturers (denoted by $C, B, G, F A$, and FT) were tested and compared. The FA and FT mirrors were from the same manufacturer, but silvered on the atmosphere and the tin rich side of the float glass respectively. 
Boiling Water

Mirror samples $5 \times 5 \mathrm{~cm}(2 \times 2$ in.) from each manufacturer were vertically suspended in a beaker of deionized water. The lower half of the mirror sample was immersed in the water. Vertical lines were scribed along the entire length of the mirror, with a grid section scribed well above the water level and another grid below the water level. The beaker was covered with a watch glass to prevent extensive evaporation of the water during the test. The water was heated to boiling and maintained at that temperature throughout the test.

Samples were monitored every hour for $8 \mathrm{hr}$. Degradation of the mirrors occurred quite rapidly (within the first $2 \mathrm{hr}$ ) at the silver/glass interface on some scribed lines. This degradation was not uniform across all the scribed lines on a given sample or on all the samples from a given manufacturer, so its significance is unclear. It may have been a function of the depth and severity of the scribed line rather than the mirror type.

After longer periods of time, one-half day or more, some uniform degradation occurred on nearly all the scribed lines just above the water level as seen in the scattered light photograph (Figure 15). At the end of the first run, the FT mirrors showed the most severe degradation and the $C$ mirrors showed the least damage. The other three mirror types performed about the same.

A subsequent experiment was conducted over a 5-day period. Again, within $2 \mathrm{hr}$, non-uniform degradation appeared on three of the samples ( $B$, FT and $G$ ). The FA and $C$ samples showed no damage. After $18 \mathrm{hr}$ the FA, FT and G samples showed uniform damage at the vapor/liquid line. After $24 \mathrm{hr}$, all the mirrors showed some such damage. In this trial the $B$ sample gave the worst performance and the $C$ sample again showed the least amount of damage. The other samples showed similar amounts of damage. The initial non-uniform degradation observed in this run appeared to have little correlation with the final results of the test. 


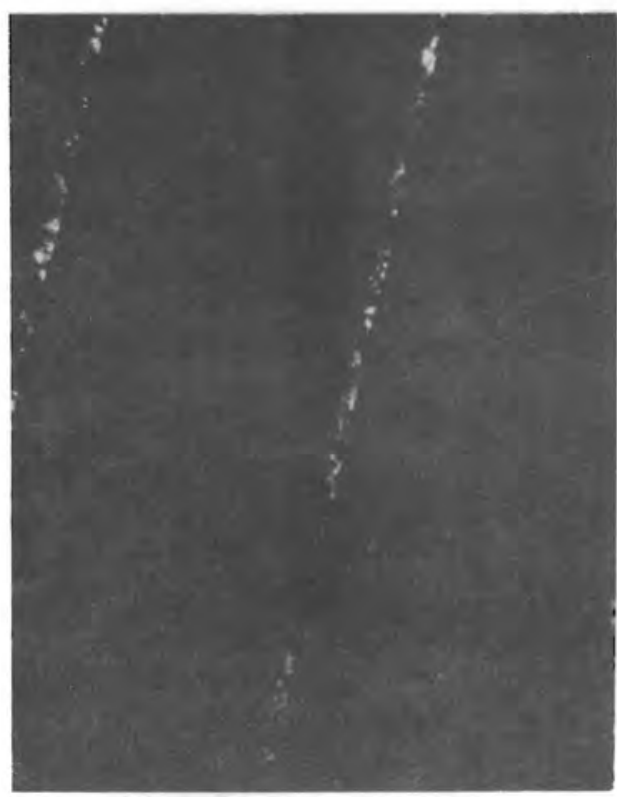

SAMPLE BEFORE IMMERSION

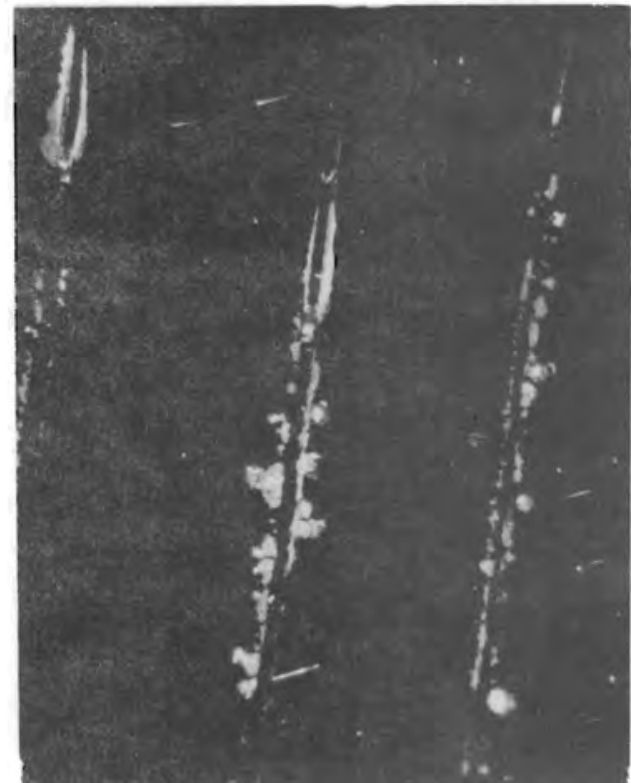

SAMPLE AFTER 20 HOURS IN BOILING $\mathrm{H}_{2} \mathrm{O}$

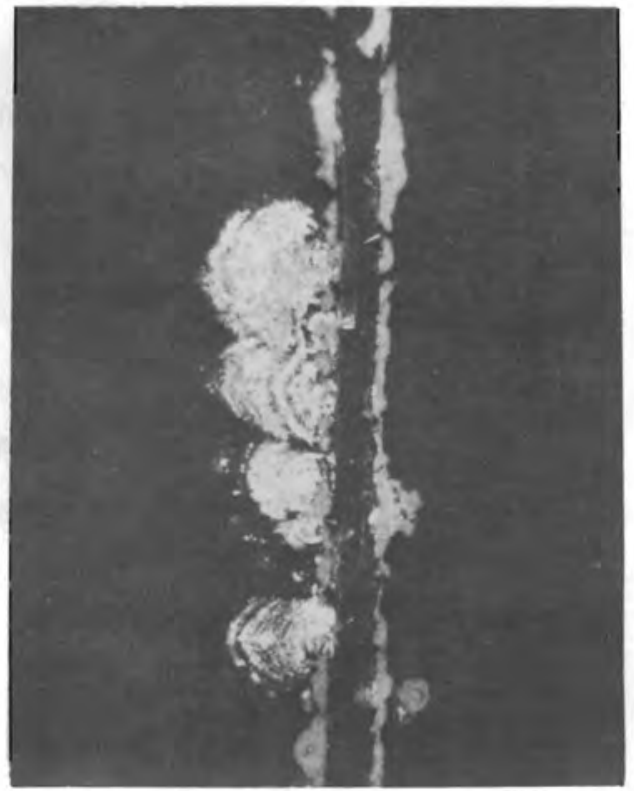

SAMPLE AFTER 20 HOURS IN BOILING $\mathrm{H}_{2} \mathrm{O}$

FIGURE 15. Mirror Samples Before and After Partial Immersion in Boiling $\mathrm{H}_{2} \mathrm{O}$ 
Salt Spray

For this test, two $5 \times 10 \mathrm{~cm}(2 \times 4$ in. ) mirror samples from each manufacturer were mounted vertically on a rotating carousel, paint side facing outwards. As the samples rotated, they were sprayed with a $1 \%$ salt solution. Two diffuse blowers dried each sample before it was again sprayed with the salt solution. Two heat lamps were mounted around the carousel and kept the ambient air temperature at approximately $32^{\circ} \mathrm{C}\left(90^{\circ} \mathrm{F}\right)$. One complete salt water spray and dry cycle took approximately one minute. The mirror samples were positioned so that part of the sample was directly sprayed with the salt solution and part was above the direct spray line. The part of the sample above the direct spray line was subject to some misting by the sprayed salt solution. Lines were scribed along the entire length of each sample and grid sections were scribed both within the directly sprayed section and above it.

Some degradation was apparent on most of the samples after $24 \mathrm{hr}$. Degradation was initiated just above the spray line. Salt deposits built up along and above this line (see Figure 16). Deposits below this line were washed away with the repeated spraying so significant amounts of salt did not accumulate. Damage first occurred along the scribed lines where the salt deposits built up. This damage area gradually spread, first along the scribed lines and then undercut the paint and spread to the rest of the mirror.

Samples from the same manufacturer did not always show the same amounts of degradation. Despite this, at the end of the 4-day test, it was clear that the $G$ mirrors showed the least amount of damage (see Figure 17). The other samples showed essentially the same amount of deterioration as shown in Figures 18-21.

\section{Acid Vapor}

For all the acid vapor tests $\left(\mathrm{HCl}, \mathrm{HNO}_{3}\right.$, and $\left.\mathrm{H}_{2} \mathrm{SO}_{4}\right)$, mirrors were cut into $2.5 \times 5 \mathrm{~cm}(1 \times 2$ in. $)$ samples, cleaned, scribed with a grid pattern in the center of the sample, rinsed with deionized water and allowed to dry. Figure 22a shows a prepared sample before exposure to any vapor. Figure 23 is a magnified view of the prepared sample. The samples were then suspended, 


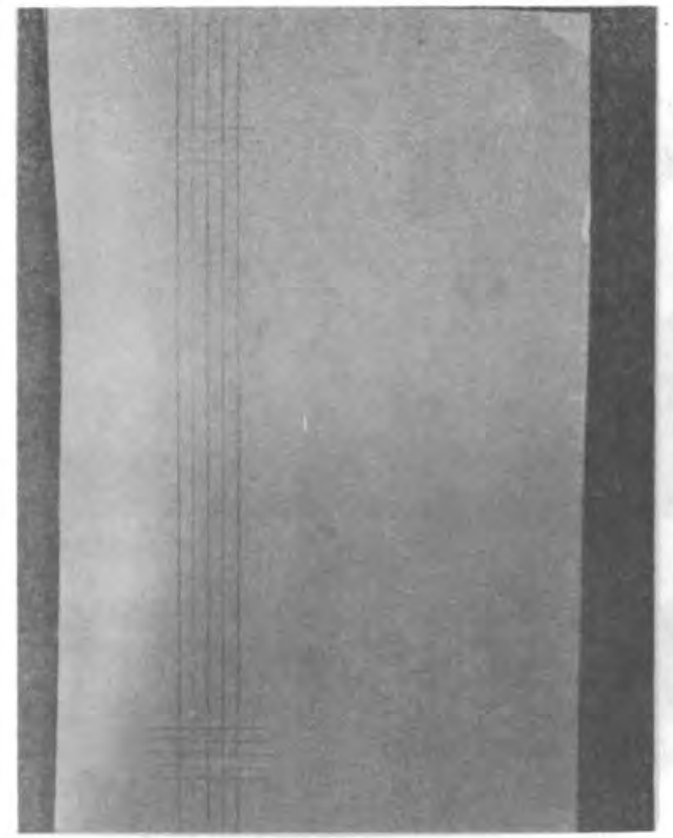

MIRROR SCRIBED

PRIOR TO EXPOSURE

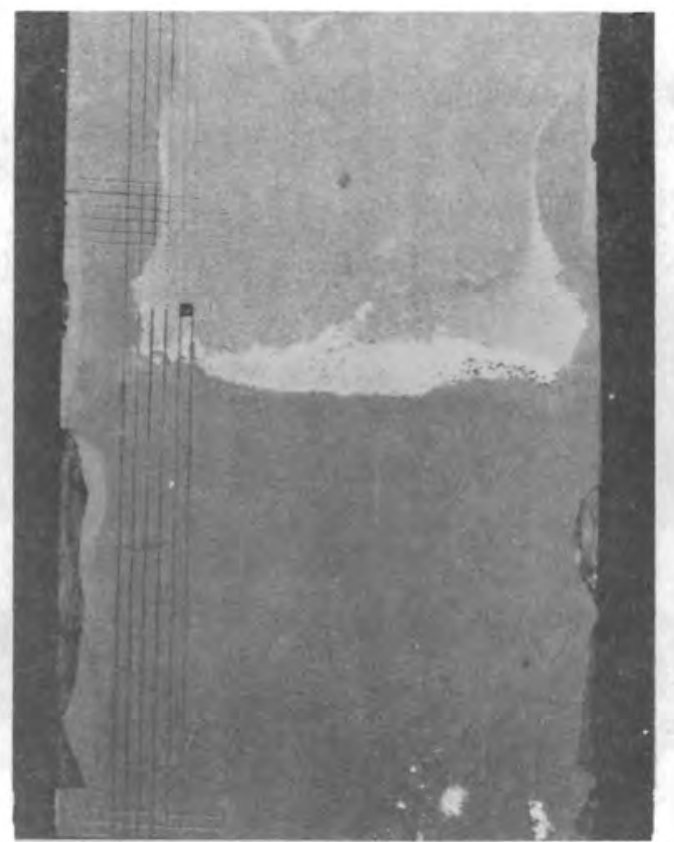

SALT BUILDUP

AFTER 24 HOURS

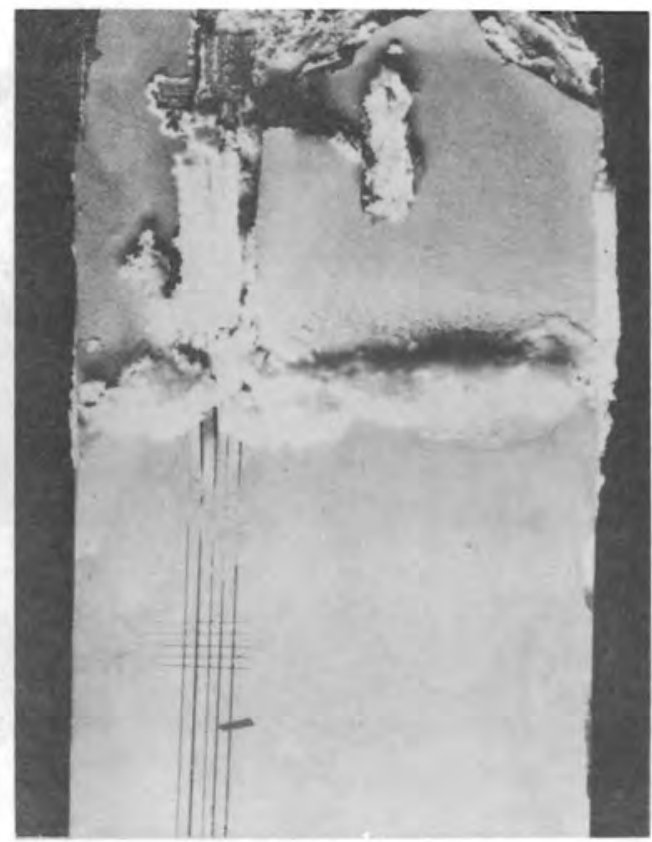

SALT BUILDUP AFTER ONE WEEK

FIGURE 16. One Percent Solution Salt Spray Test (Back Side of Mirror) 

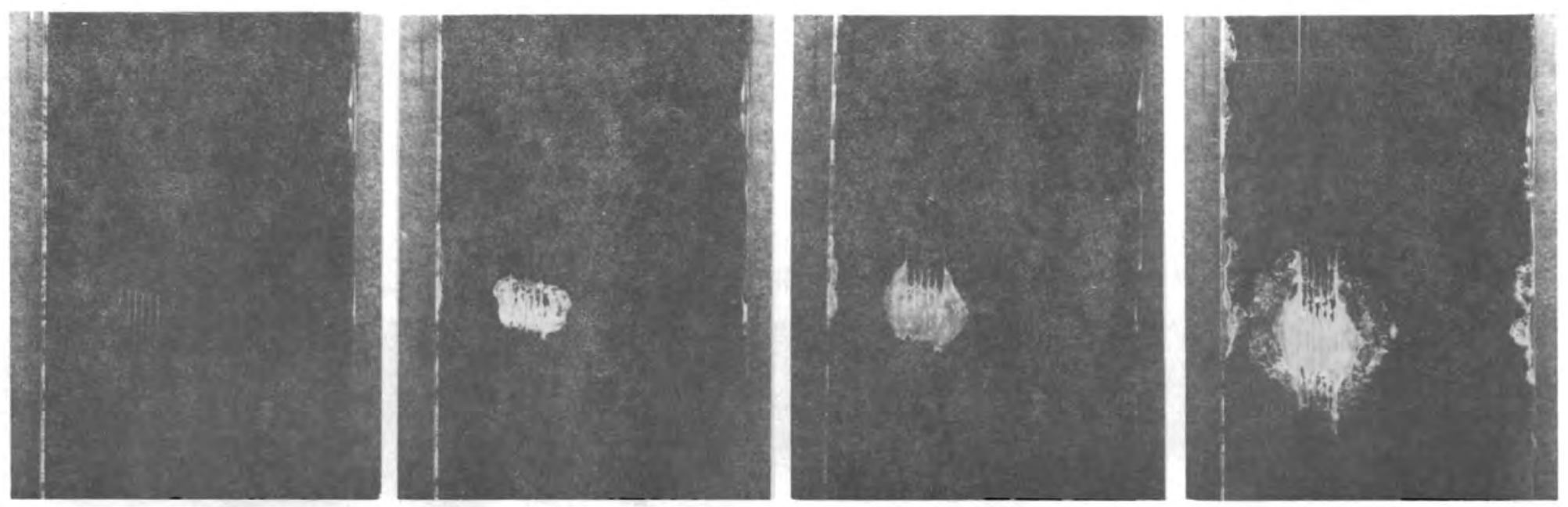

SAMPLE Gl

$\tilde{\Omega}$
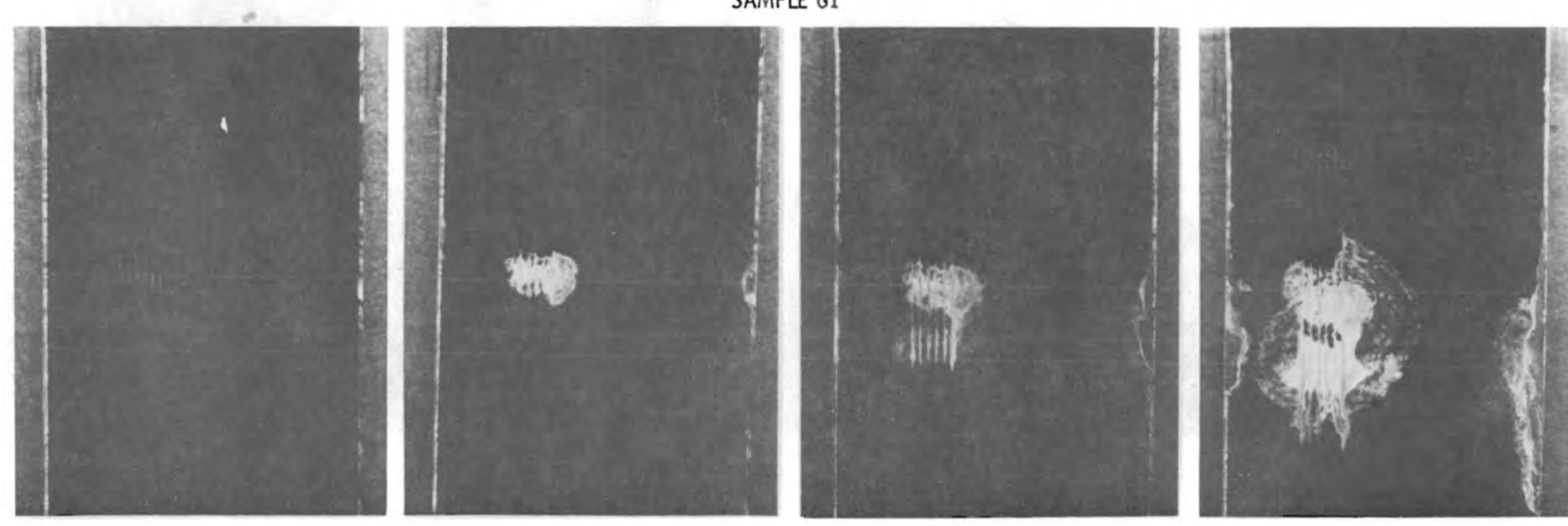

24 HOURS

48 HOURS

SAMPLE G2

72 HOURS

96 HOURS

FIGURE 17. Salt Spray Test on G Samples 

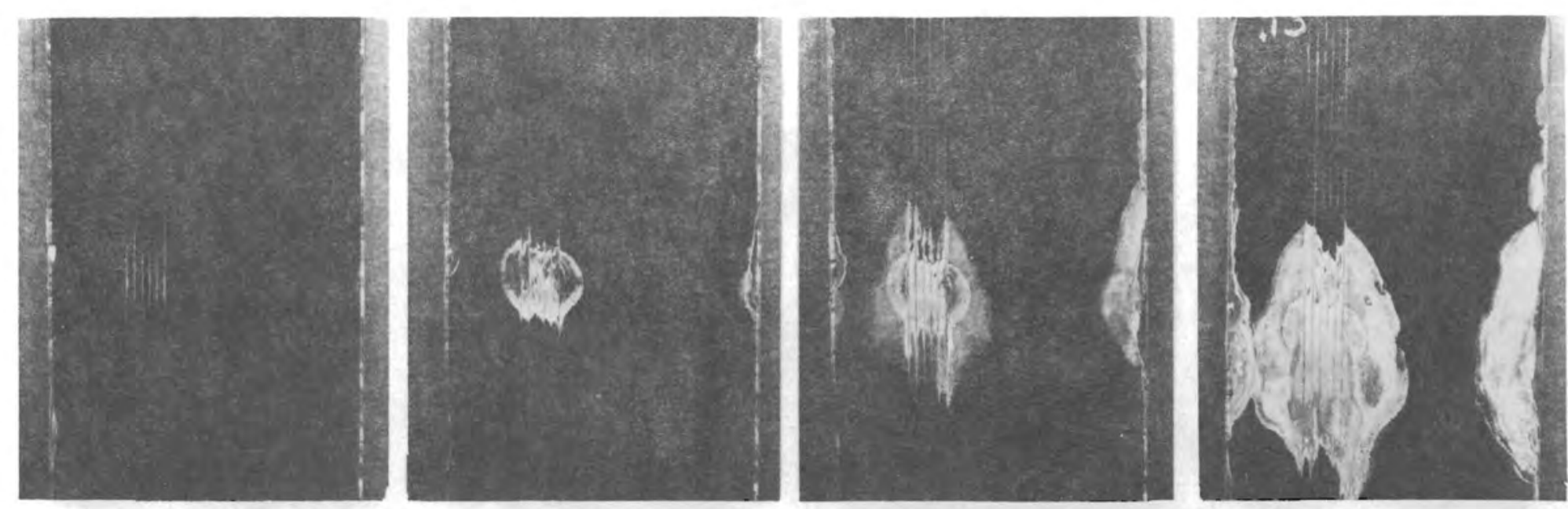

ㄱ

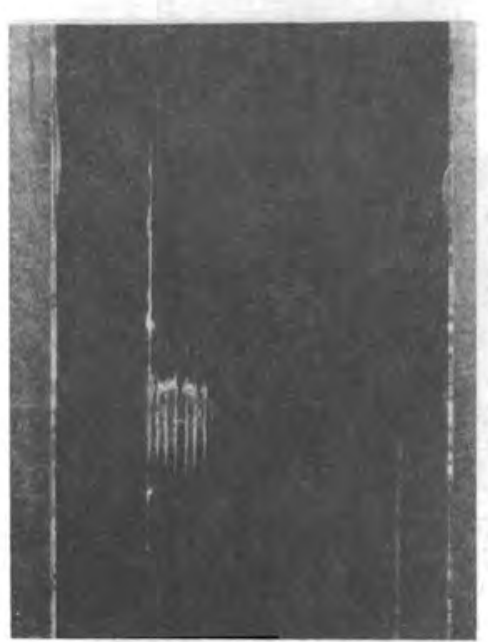

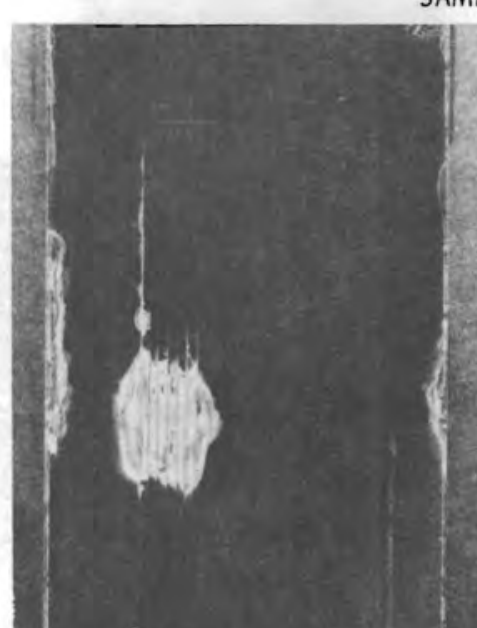

SAMPLE C2

48 HOURS

SAMPLE

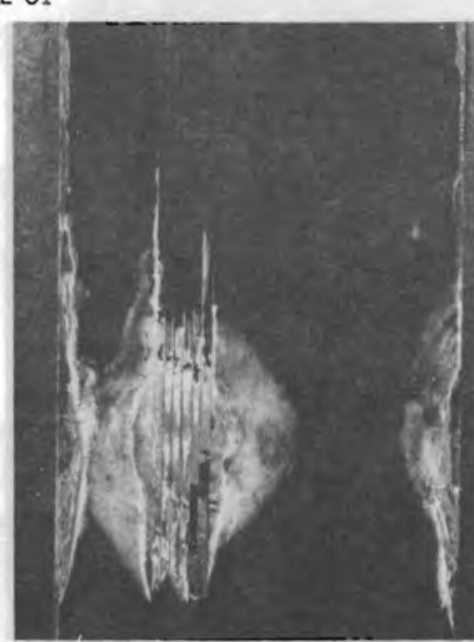

72 HOURS

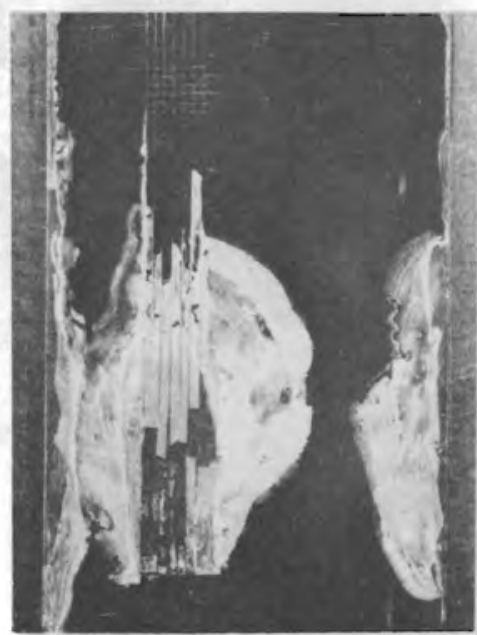

96 HOURS

FIGURE 18. Salt Spray Test on C Samples 

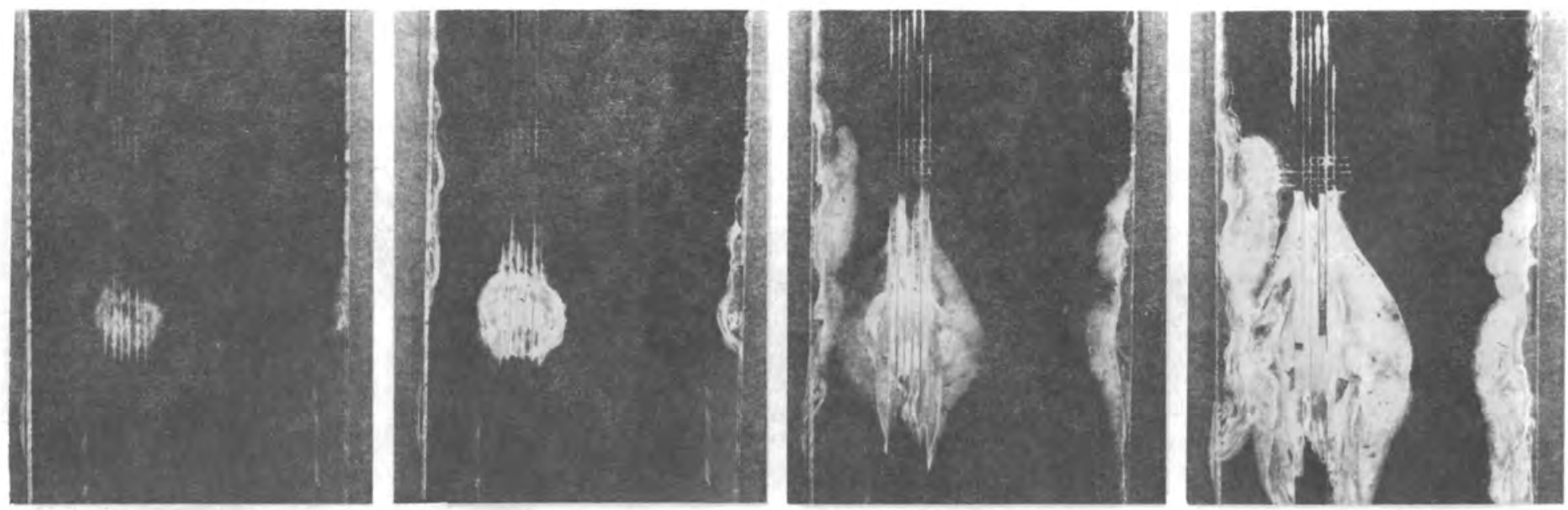

SAMPLE B1

N

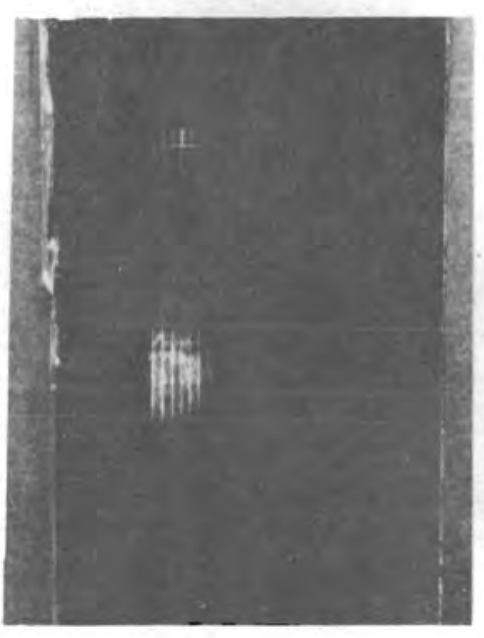

24 HOURS

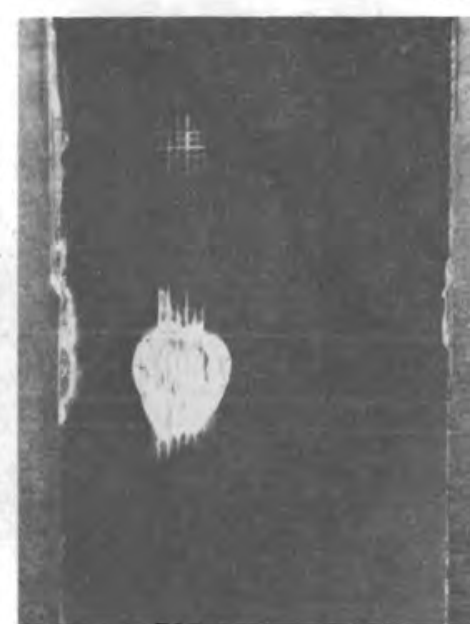

SAMPLE B2

48 HOURS

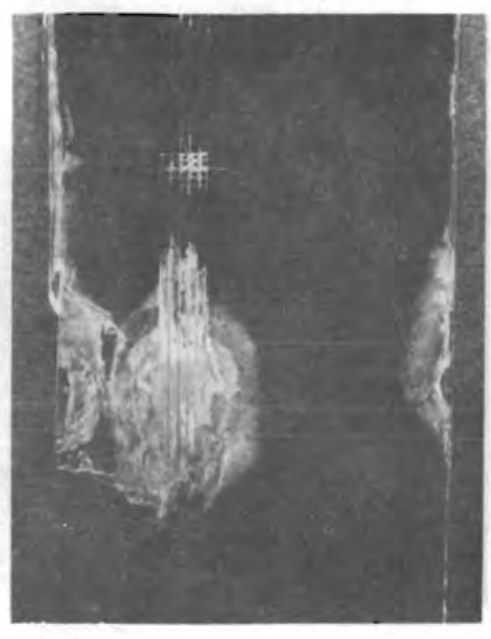

72 HOURS

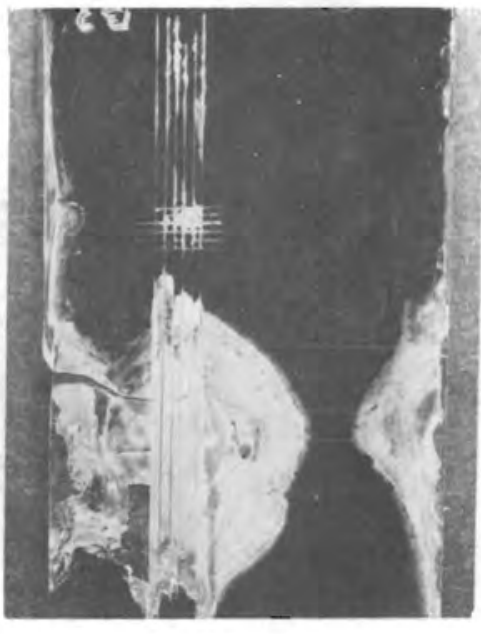

96 HOURS

FIGURE 19. Salt Spray Test on B Samples 

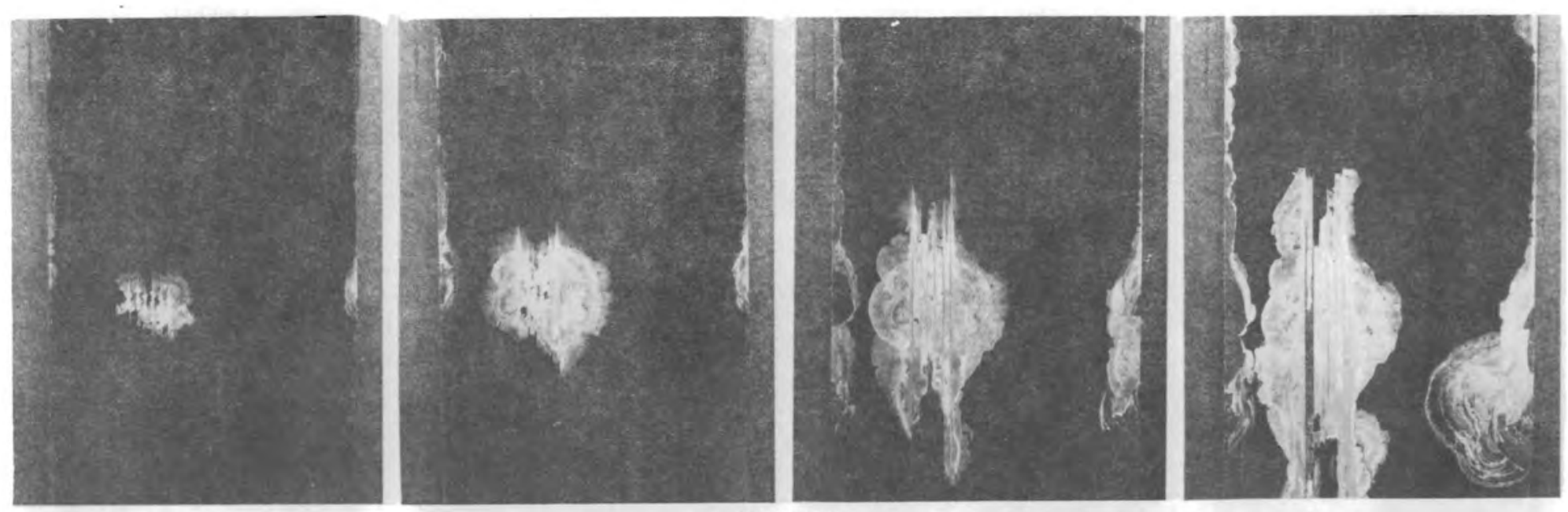

กับ

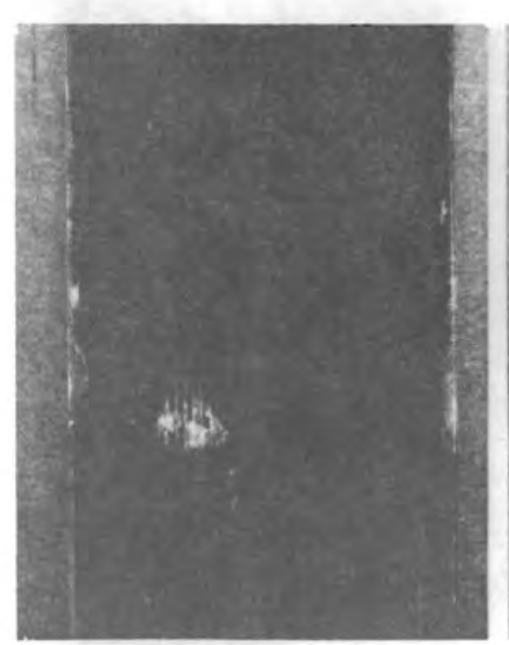

24 HOURS

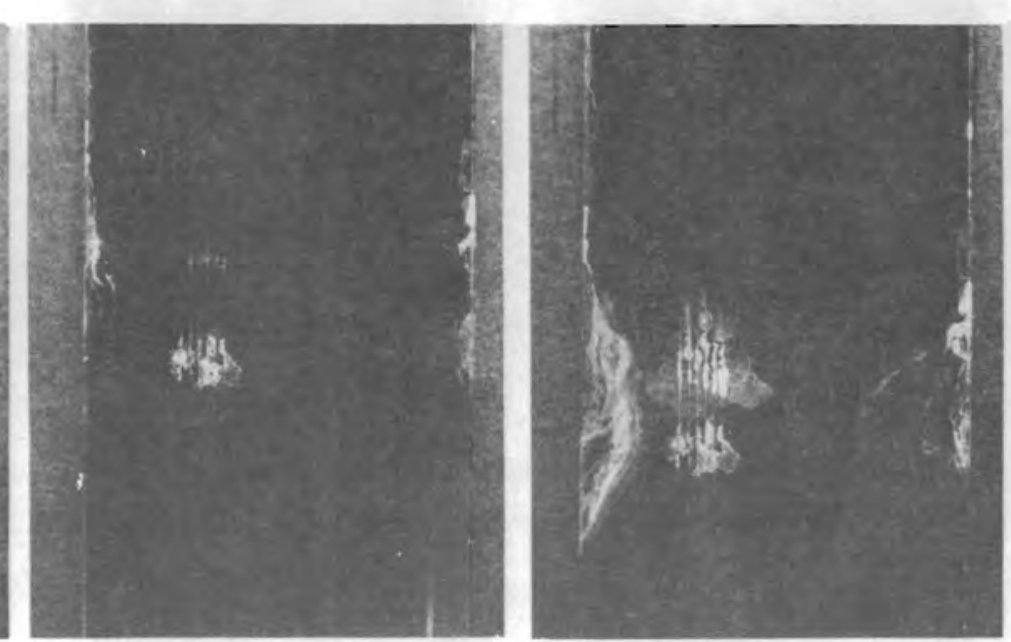

SAMPLE FA2

48 HOURS

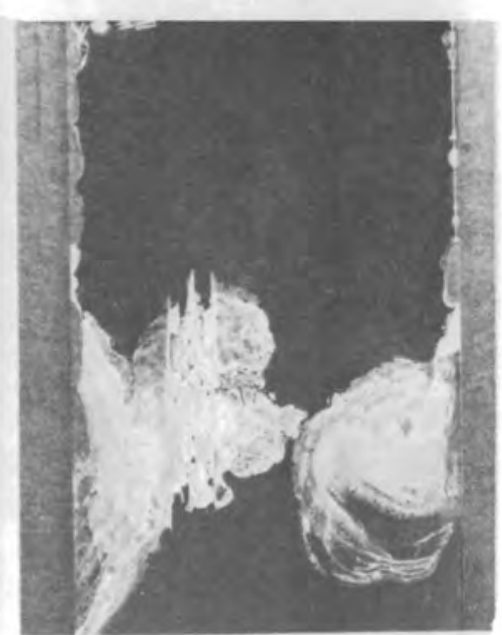

96 HOURS

FIGURE 20. Salt Spray Test on FA Samples 

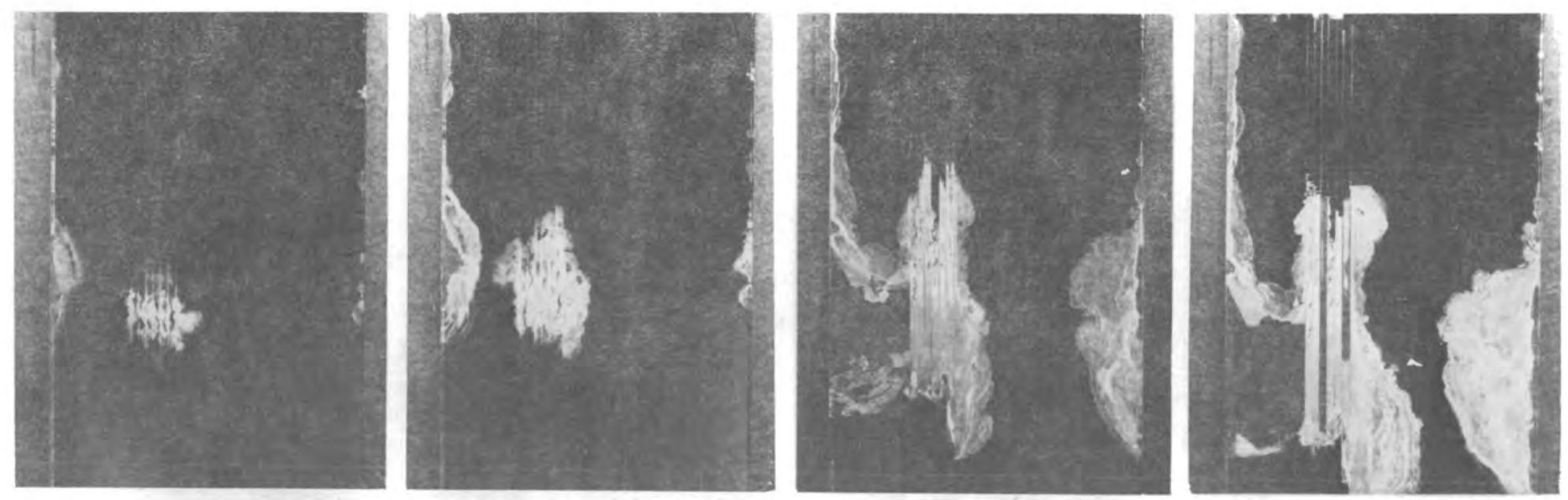

$\omega$

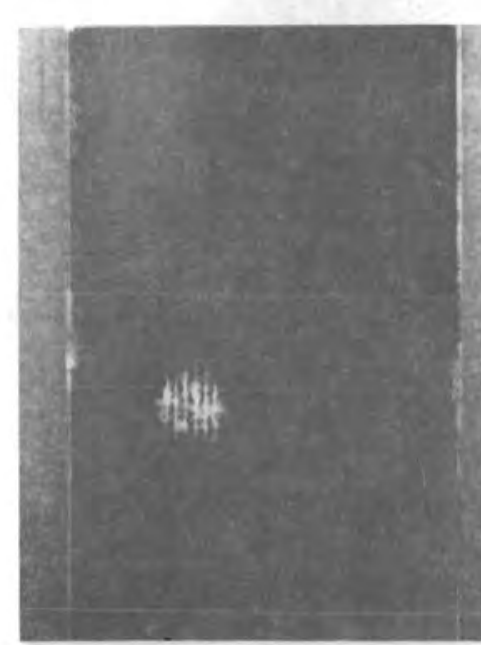

24 HOURS

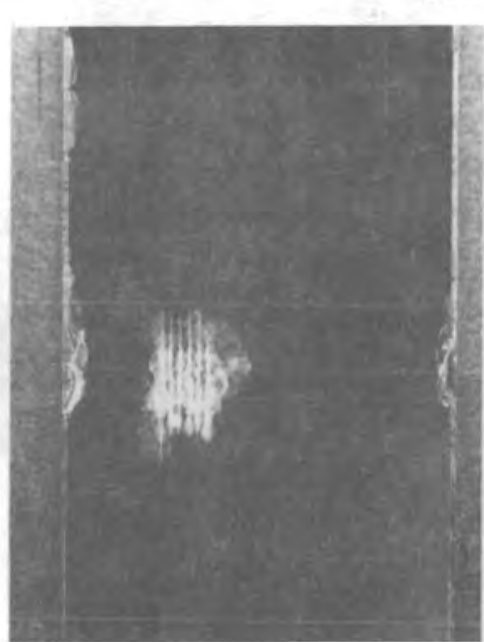

SAMPLE FT2

48 HOURS

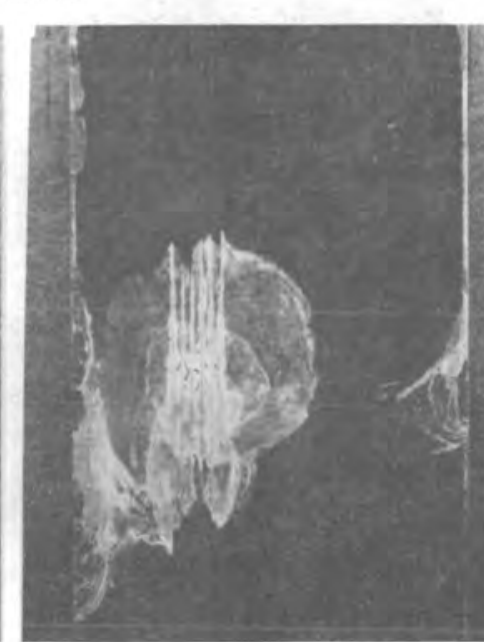

72 HOURS

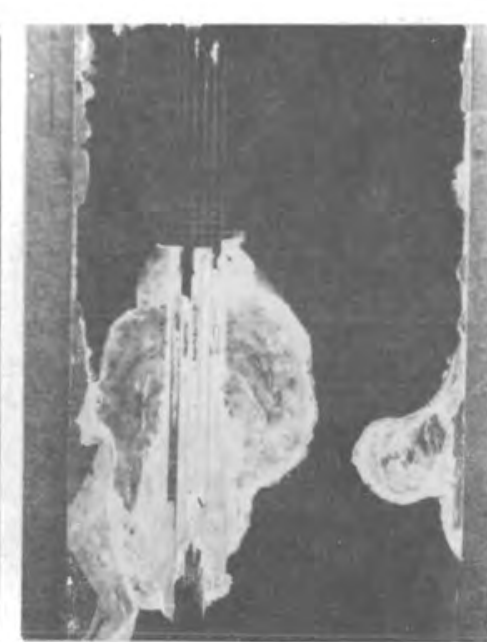

96 HOURS

FIGURE 21. Salt Spray Test on FT Samples 


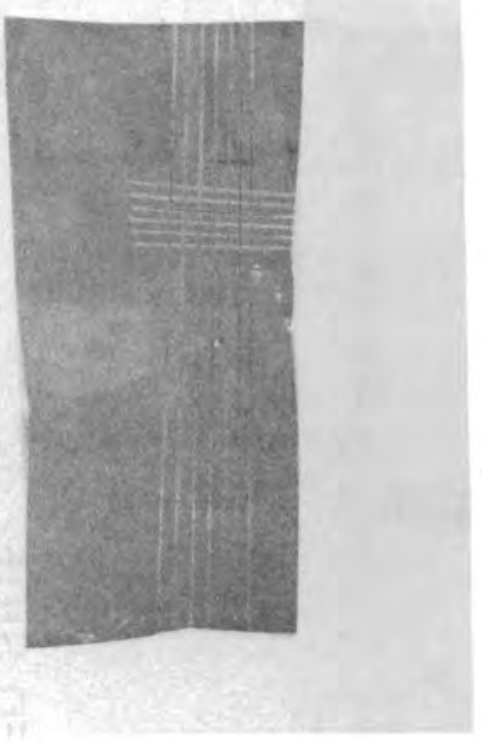

A. UNEXPOSED MIRROR

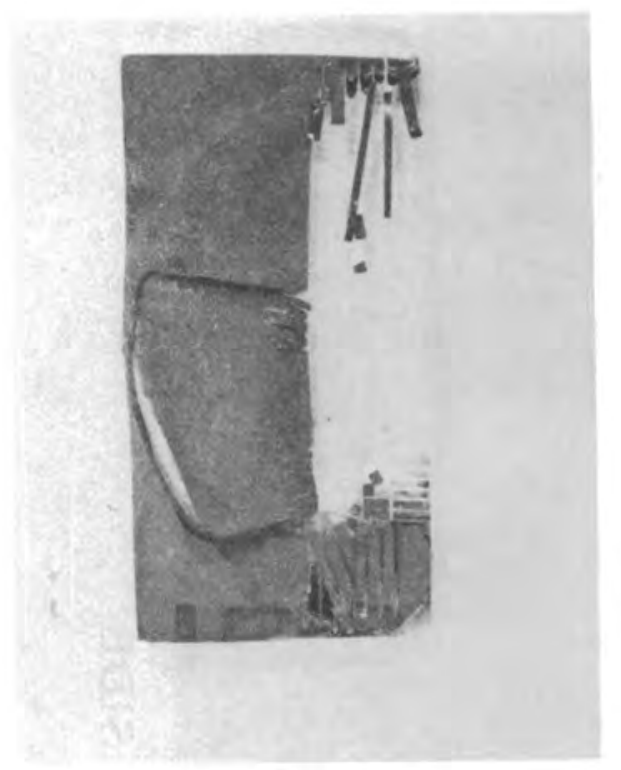

C. $\mathrm{HNO}_{3}$ VAPOR

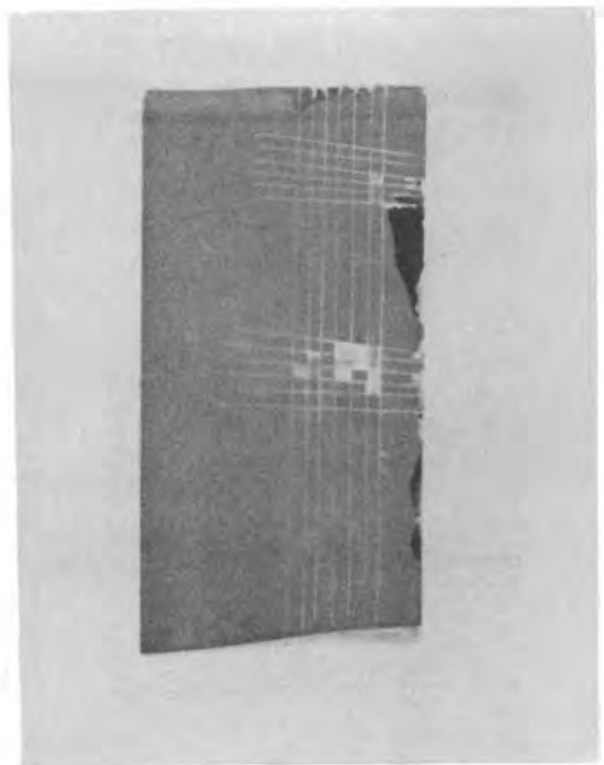

B. $\mathrm{HCI}$ VAPOR

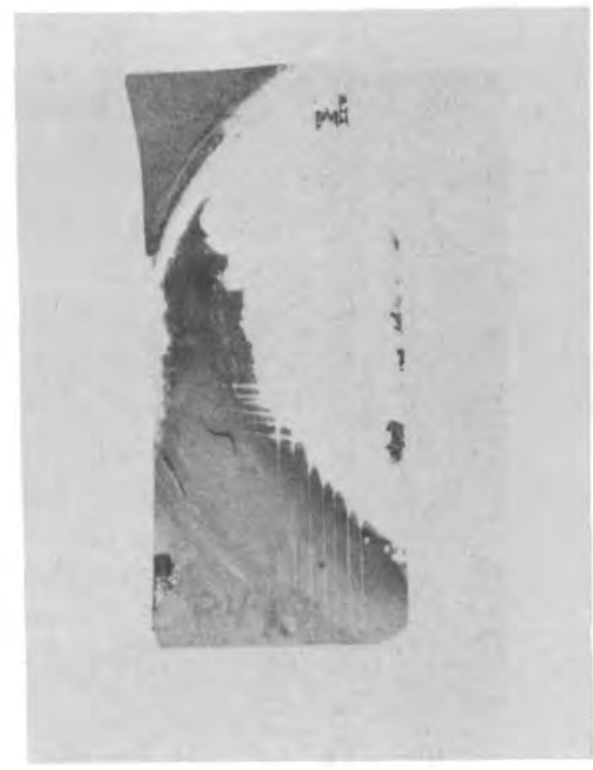

D. $\mathrm{H}_{2} \mathrm{SO}_{4}$ VAPOR

FIGURE 22. Effect of Acid Vapors on the Paint/Copper/Silver Backing of Mirrors 


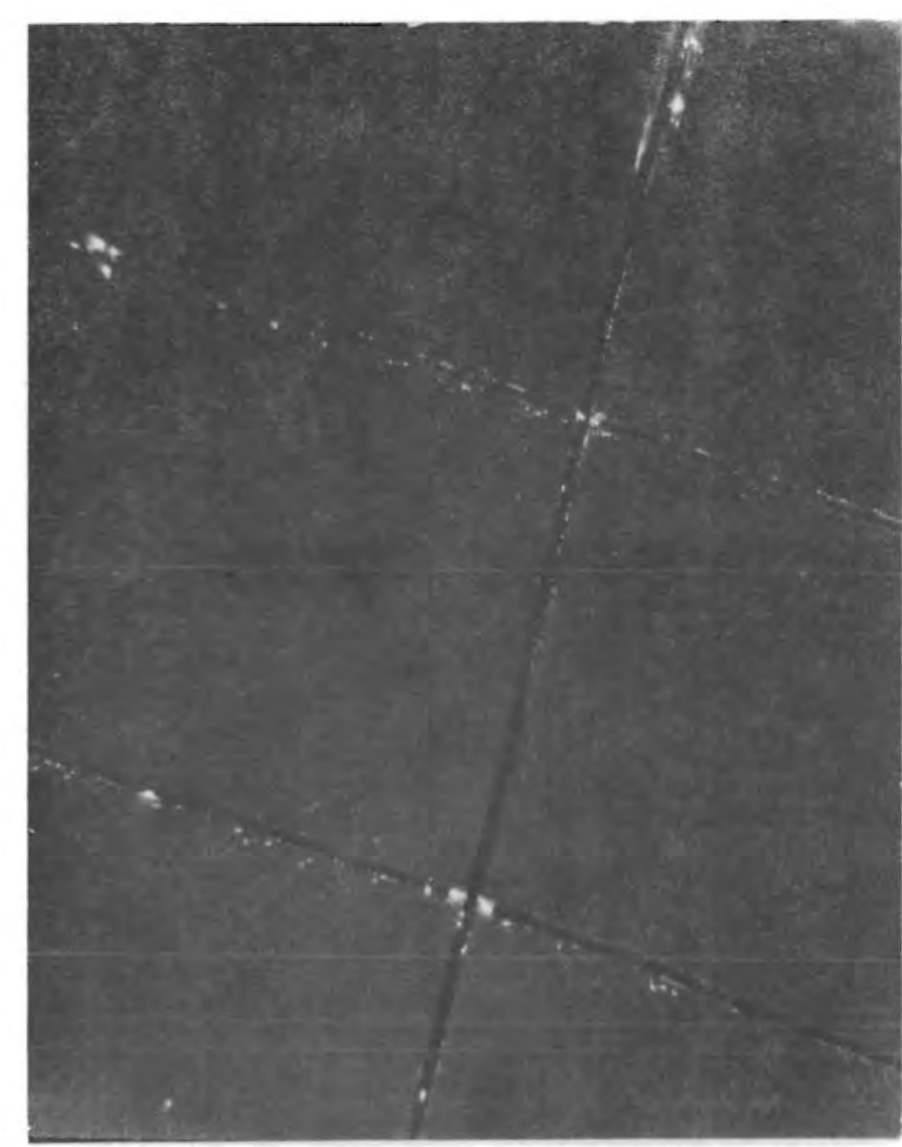

GLASS SIDE

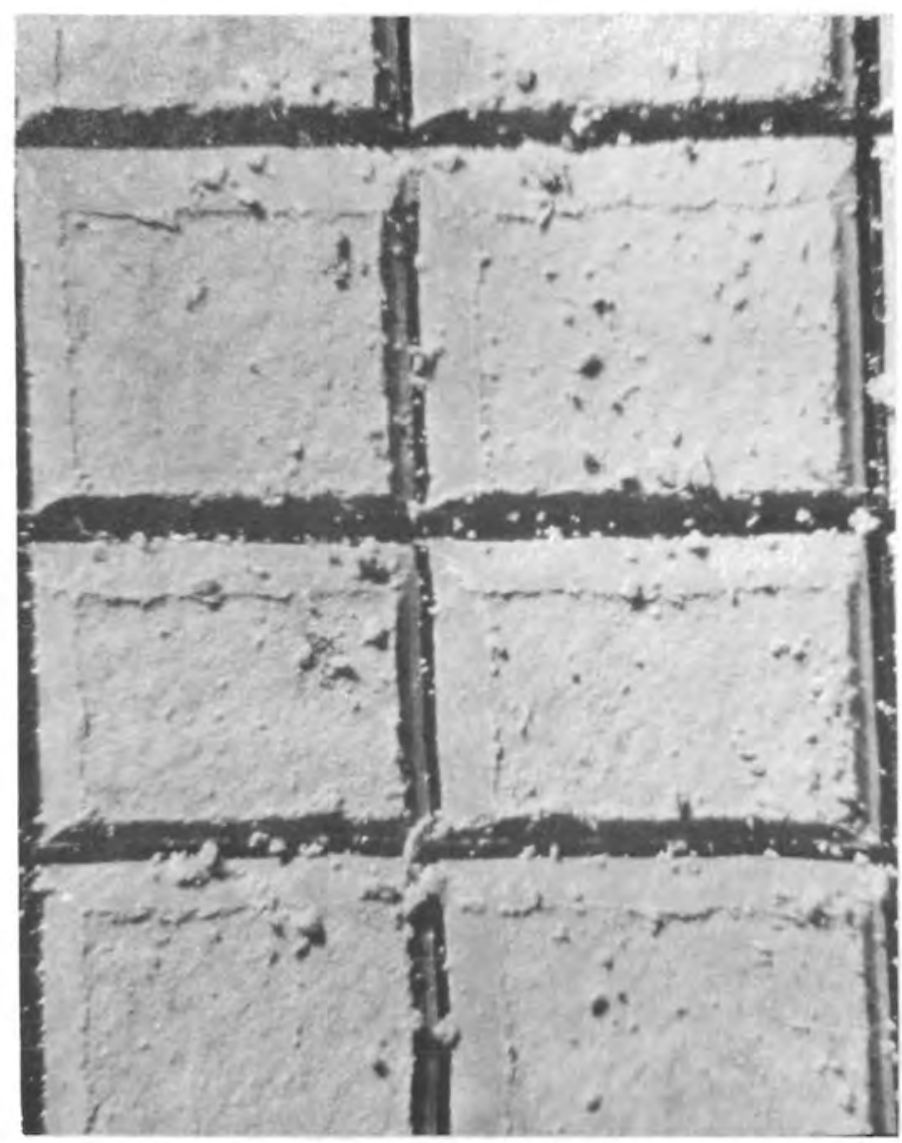

PAINTED SIDE

FIGURE 23. Mirror Sample Before Exposure to Acid Vapor (Magnified View) 
paint side down, over small petri dishes containing 2.5 to $5 \mathrm{ml}$ of concentrated acid. In this manner, the samples were exposed to vapor from the concentrated acid solutions. Upon completion of the tests, the samples were rinsed thoroughly with deionized water. They were then ranked from best performance to worst performance by visual comparison. The test results are summarized in Table 3. The parentheses in the table group samples with similar performance. The mirror samples reacted differently to each of these acids, as shown in Figure 22.

TABLE 3. Summary Comparison of Accelerated Tests on Commercially Silvered Mirrors

\begin{tabular}{|c|c|c|c|c|c|c|}
\hline & by & & $\begin{array}{l}\text { ve Rar } \\
\text { Perfo }\end{array}$ & & & \\
\hline Type of Test & Worst & & & & Best & Exposure Time \\
\hline Boiling Water & FT & (B & FA & G) & C & $12 \mathrm{Hrs}$ \\
\hline & B & (FT & G & FA & C & $120 \mathrm{Hrs}$ \\
\hline Salt Spray $\left(100^{\circ} \mathrm{F}\right)$ & (FT & FA & B & C) & G & $96 \mathrm{Hrs}$ \\
\hline Moist $\mathrm{H}_{2} \mathrm{SO}_{4}$ Vapor & (c & G) & (FT & B & FA) & $90 \mathrm{Min}$ \\
\hline HCl Vapor & B & (FA & FT) & G & c & $45 \operatorname{Min}$ \\
\hline & FT & (G & B & C) & FA & $30 \mathrm{Min}$ \\
\hline & G & FA & FT & B & C & $35 \mathrm{Min}$ \\
\hline & $\mathrm{FT}$ & (FA & B) & G & C & $30 \mathrm{Min}$ \\
\hline & FT & (FA & B) & C & G & $60 \mathrm{Min}$ \\
\hline $\mathrm{HNO}_{3}$ Vapor & FA & C & $\mathrm{FT}$ & (B & G) & $80 \operatorname{Min}$ \\
\hline & FT & (FA & B) & C & G & 45-100 Min \\
\hline
\end{tabular}

Small samples approximately one centimeter square were also scribed and tested. These samples were analyzed for residual materials using a scanning electron microscope (SEM) with an EDX attachment. SEM/EDX analysis and pictures of a sample prior to vapor testing is shown in Figure 24. 


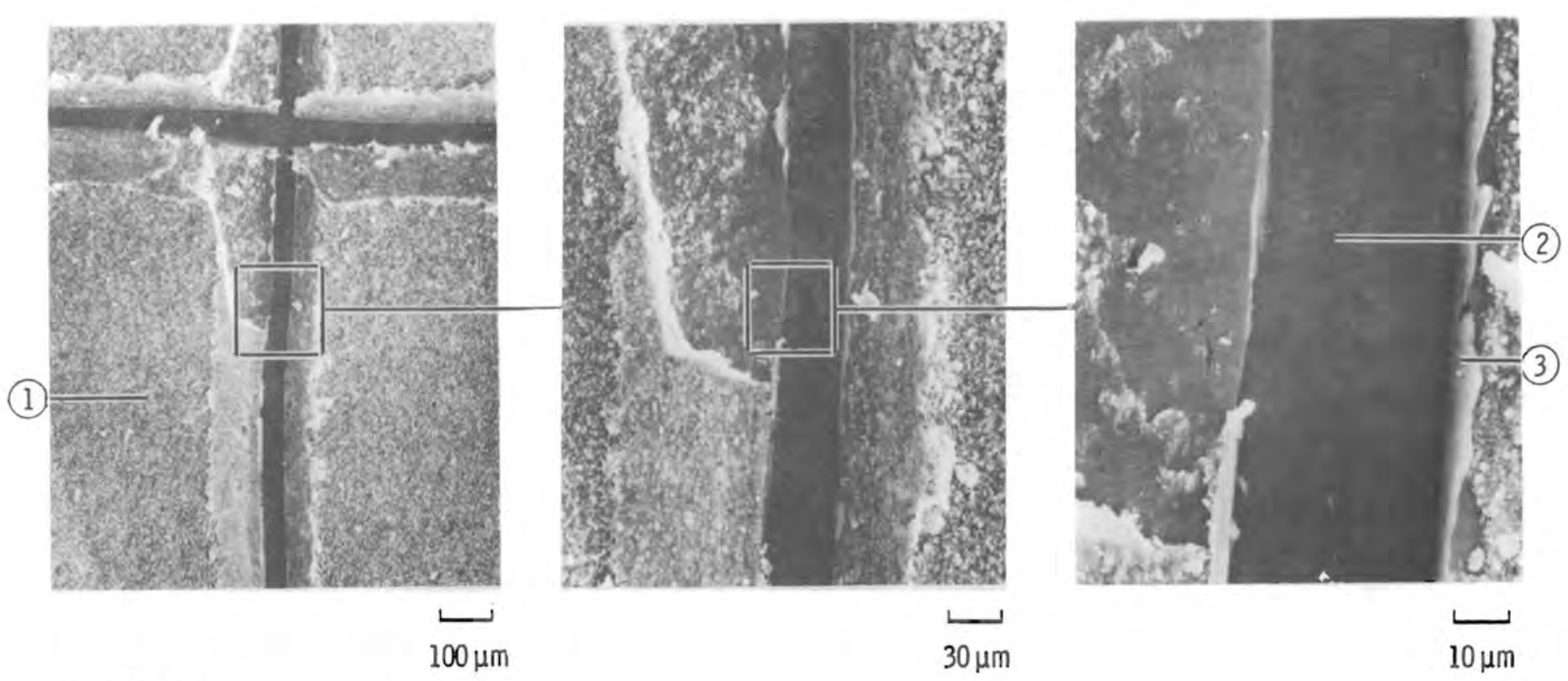

EDX ANALYSIS

1. PAINT ( $\mathrm{Si}, \mathrm{Pb}, \mathrm{S}, \mathrm{Ba}, \mathrm{Ti}$ ? AND SMALL AMOUNTS OF $\mathrm{Mg}, \mathrm{Al}, \mathrm{Fe}$ )

2. $\operatorname{GLASS}(\mathrm{Si}, \mathrm{Ca}, \mathrm{Na}, \mathrm{Mg})$

3. $\mathrm{Ag}, \mathrm{Cu}, \mathrm{GLASS}$ AND SMALL AMOUNTS OF Pb OR $\mathrm{S}$

FIGURE 24. Commercially Silvered Mirror after Scribing and Prior to Vapor Tests 
$\underline{\mathrm{HCl}}$

The HCl vapor attacked the mirrors primarily along the scribed lines. The deterioration worstened fairly steadily with increased exposure times as can be seen in Figure 25. The $\mathrm{HCl}$ acid test produced quite uniform degradation on the different manufacturer's samples as shown in Figure 26. Performance results from one trial to another were somewhat inconsistent. The $C$ samples seemed to perform consistently well in terms of ability to withstand $\mathrm{HCl}$ acid vapor attack. The FT samples were often the worst. G samples sometimes did quite well and sometimes were the worst. FA samples usually ranked in about the middle of the group, but on one set of tests gave the best performance.

SEM and EDX analysis of these samples showed residual masses along the scribe lines as shown in Figures 26 and 27 . These areas tested high in silver and chlorine and are probably AgCl crystals.

$\underline{\mathrm{H}}_{2} \mathrm{SO}_{4}$

The sulfuric acid test was more complicated to perform and gave less uniform results. Increasing the exposure time to the vapor did not always result in uniform increased degradation on a sample as can be seen in Figure 28. The concentrated acid had to be diluted and heated to produce a significant amount of vapor. For this trial, $3 \mathrm{ml}$ of the concentrated $\mathrm{H}_{2} \mathrm{SO}_{4}$ was mixed with $2 \mathrm{ml}$ of deionized water and heated until a thick white vapor appeared. Initially, the acid vapor seemed to primarily attack the paint layer. The degradation was very non-uniform. Part of a sample might show severe degradation while another area on the same sample showed little or no damage. Some samples showed no effect of the vapor. After a 90-min test the $C$ and $G$ samples showed severe degradation and the other samples showed very little damage.

The SEM/EDX analysis of severely attacked areas showed that the copper and paint layer were gone. Recall that copper is soluble in hot $\mathrm{H}_{2} \mathrm{SO}_{4}$. The silver layer remained, but was undergoing attack along the scribed edges as seen in Figure 29. 


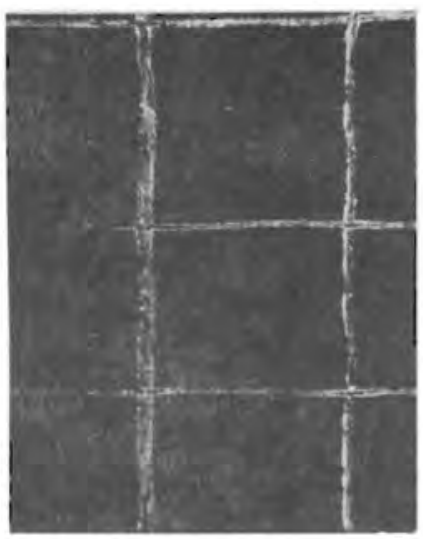

A. (5 MINUTES)

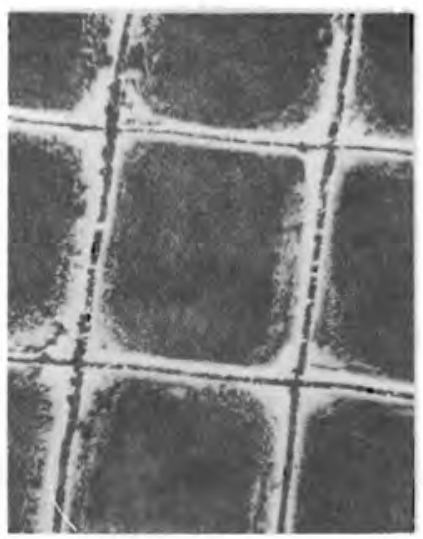

D. (20 MINUTES)

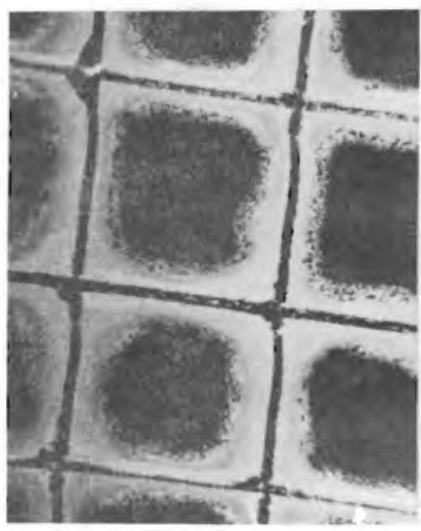

G. (35 MINUTES)

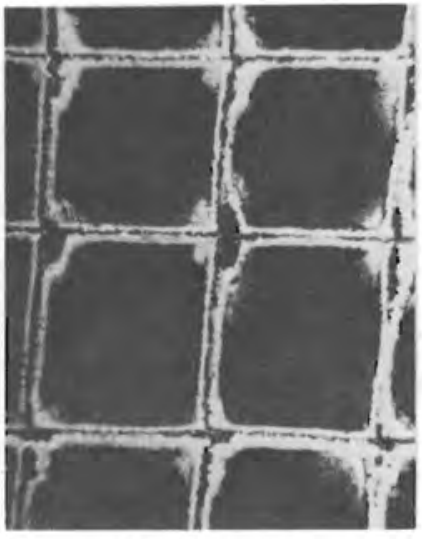

B. (10 MINUTES)

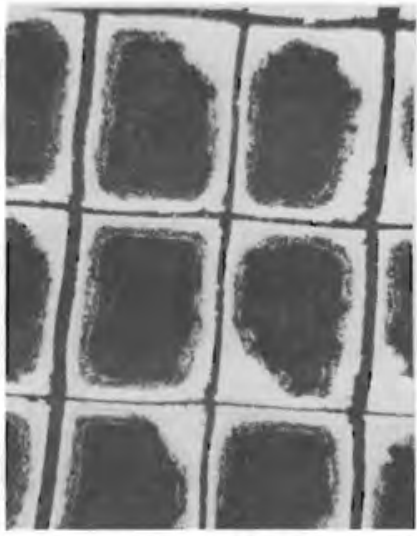

E. (25 MINUTES)

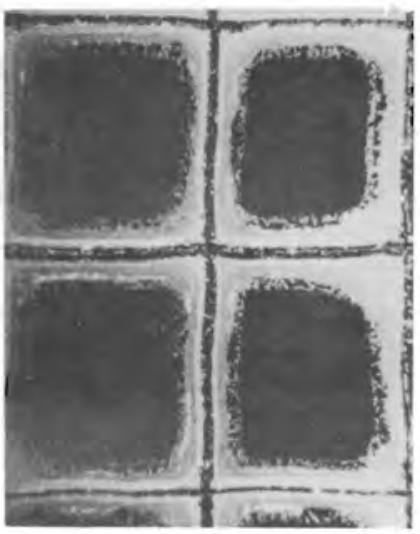

H. (40 MINUTES)

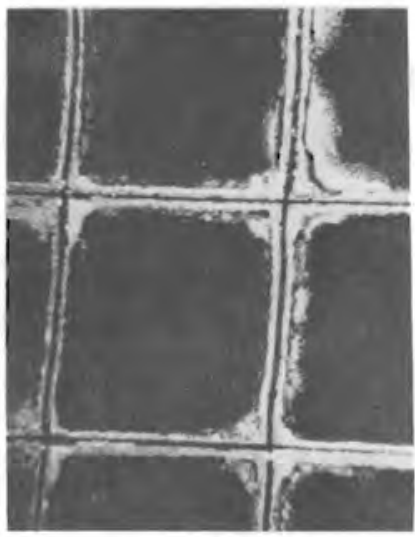

C. (15 MINUTES)

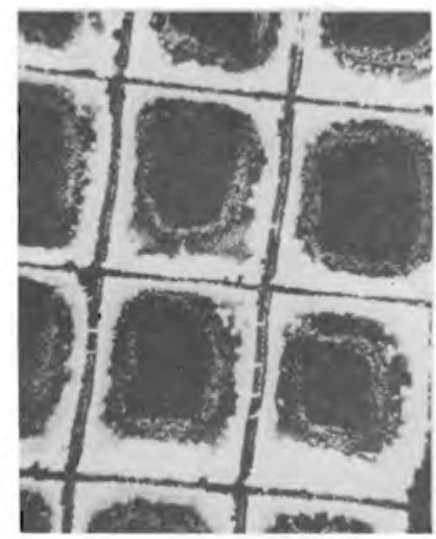

F. (30 MINUTES)

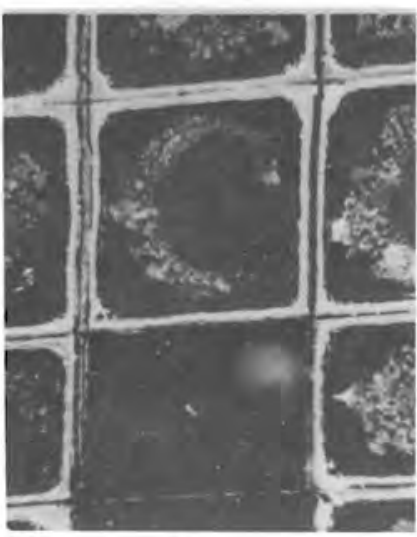

I. (70 MINUTES)

FIGURE 25. Progressive Degradation of Mirror Samples Exposed to $\mathrm{HCl}$ Vapors (Magnified View) 


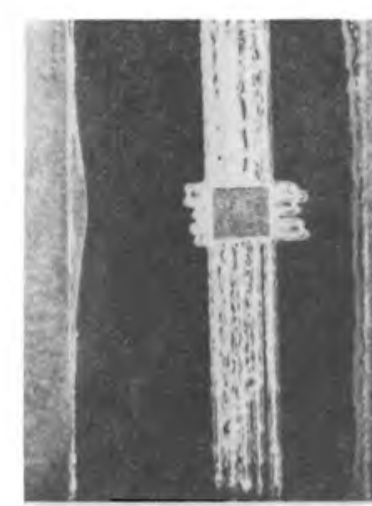

FT

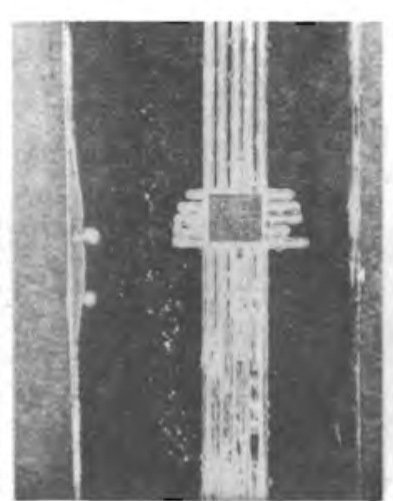

FA

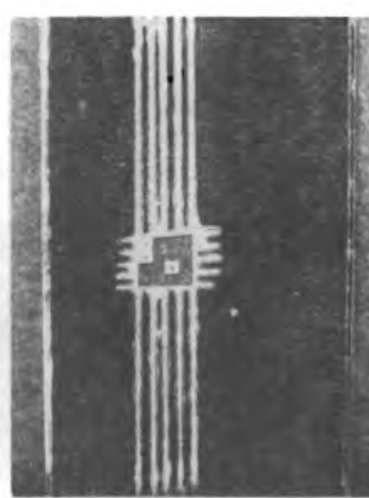

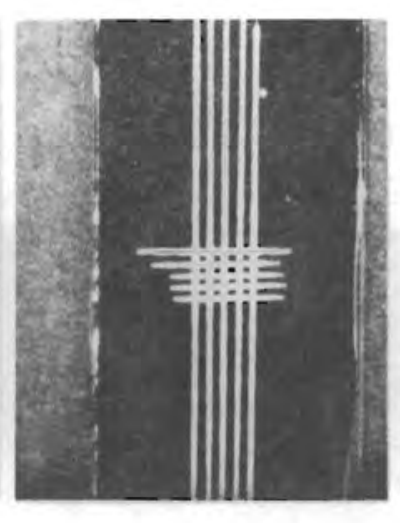

c

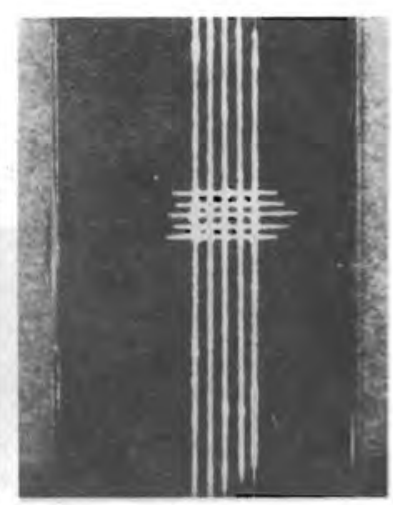

G

FIGURE 26. Commercially Silvered Mirrors ( $\mathrm{HCl}$ Vapor Test, $60 \mathrm{Min}$ ) 


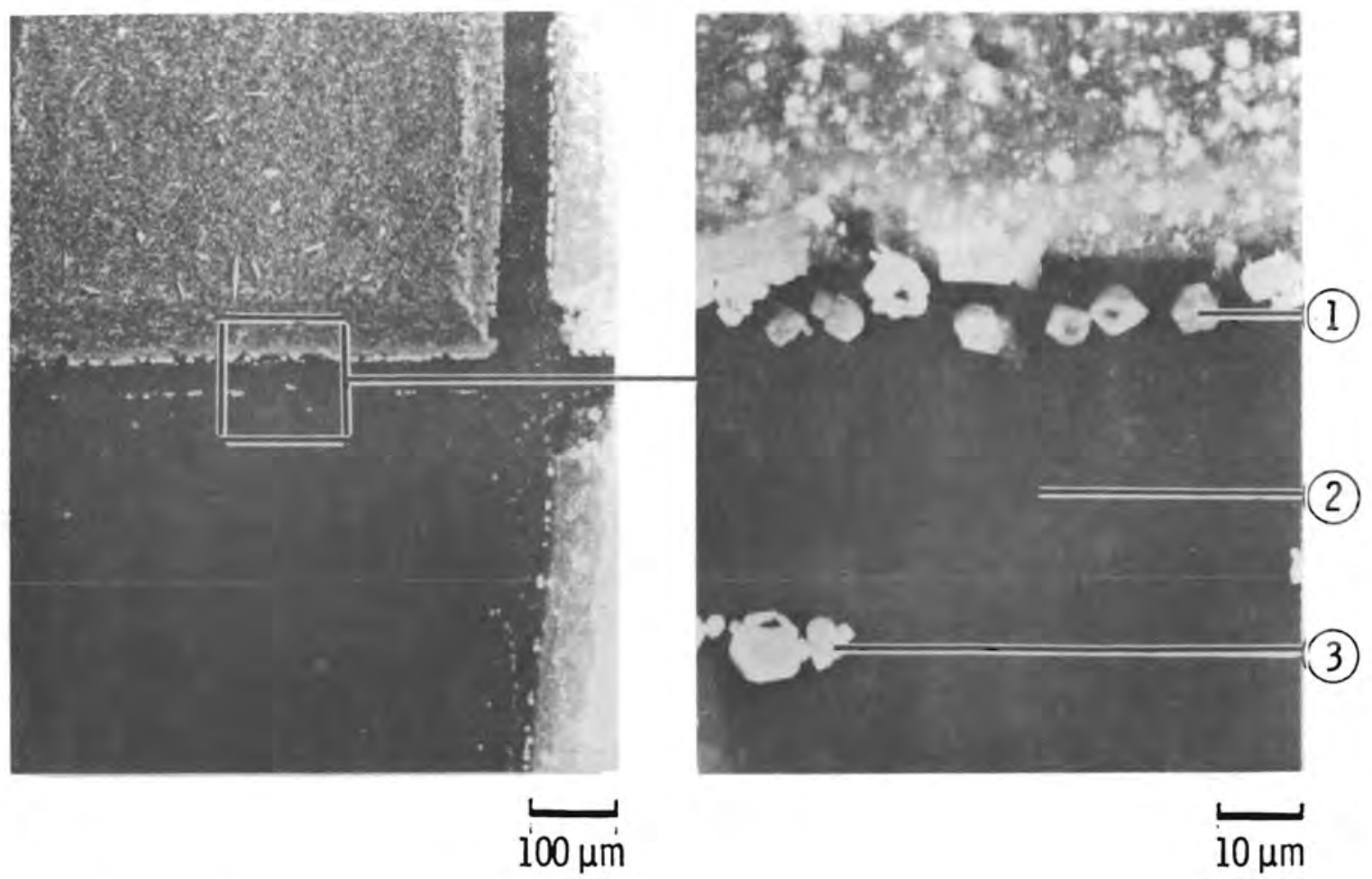

EDX ANALYSIS

1. Ag, Cl AND SMALL AMOUNTS OF Mg, Al, Si, Ba

2. GLASS

3. SAME AS I BUT LESS CI

FIGURE 27. Commercially Silvered Mirrors after HCl Vapor Test 


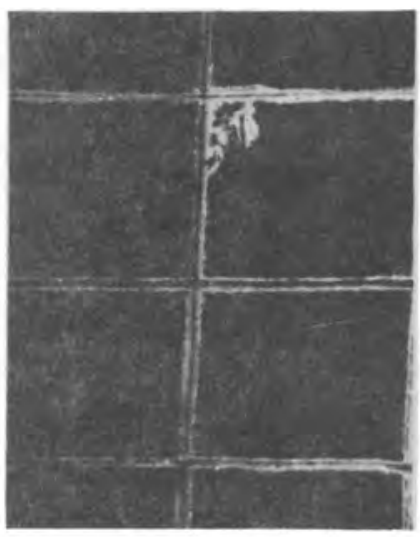

A. (10 MINUTES)

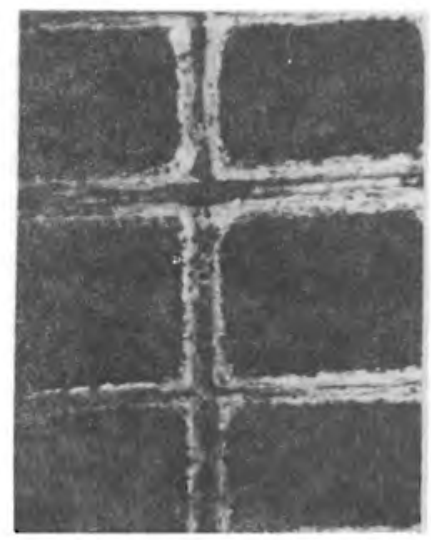

D. (40 MINUTES)

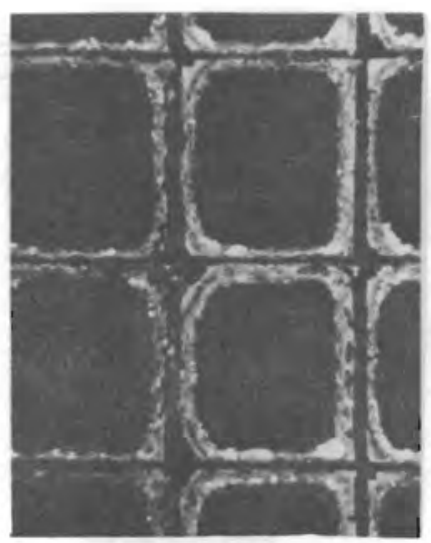

B. (20 MINUTES)

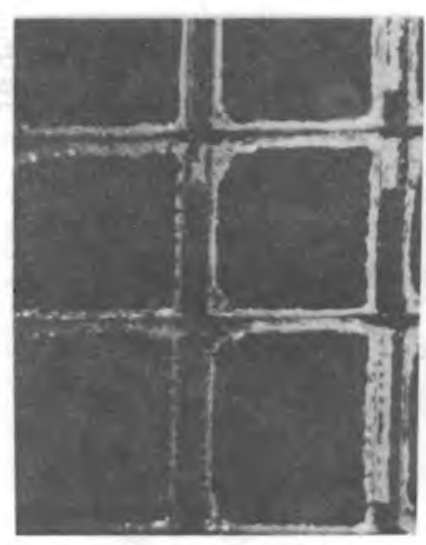

E (50 MINUTES)

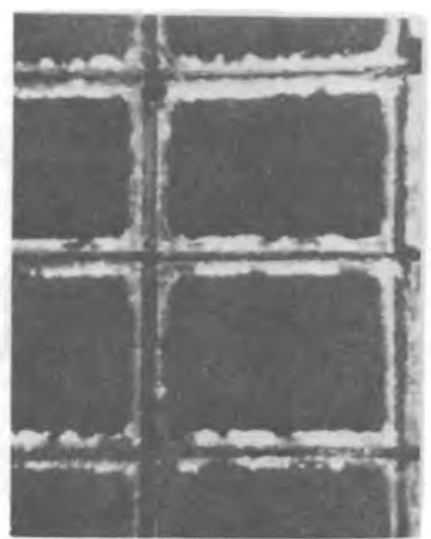

C. (30 MINUTES)

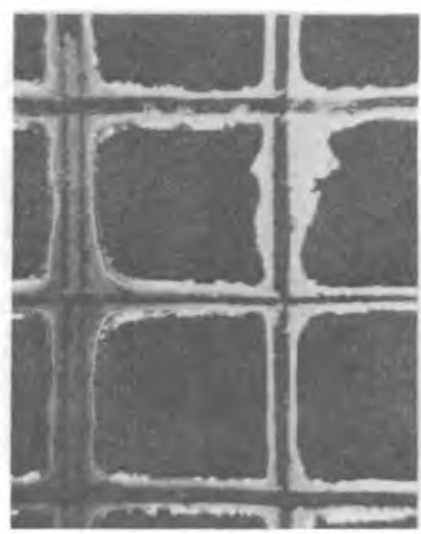

F. (60 MINUTES)

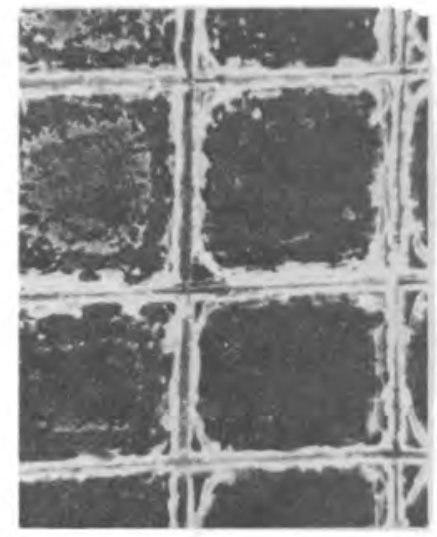

G. (70 MINUTES)

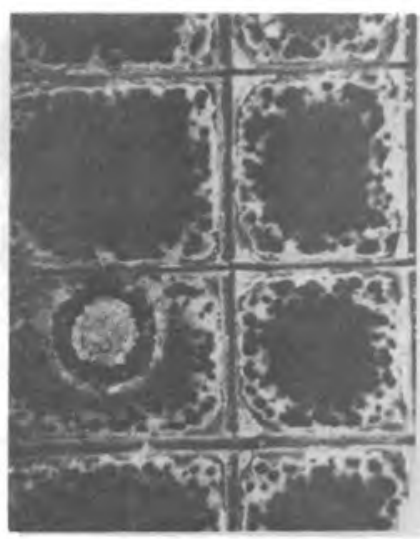

H. (95 MINUTES)

FIGURE 28. Progressive Degradation of Mirror Samples Exposed to $\mathrm{H}_{2} \mathrm{SO}_{4}$ Vapor (Magnified View) 


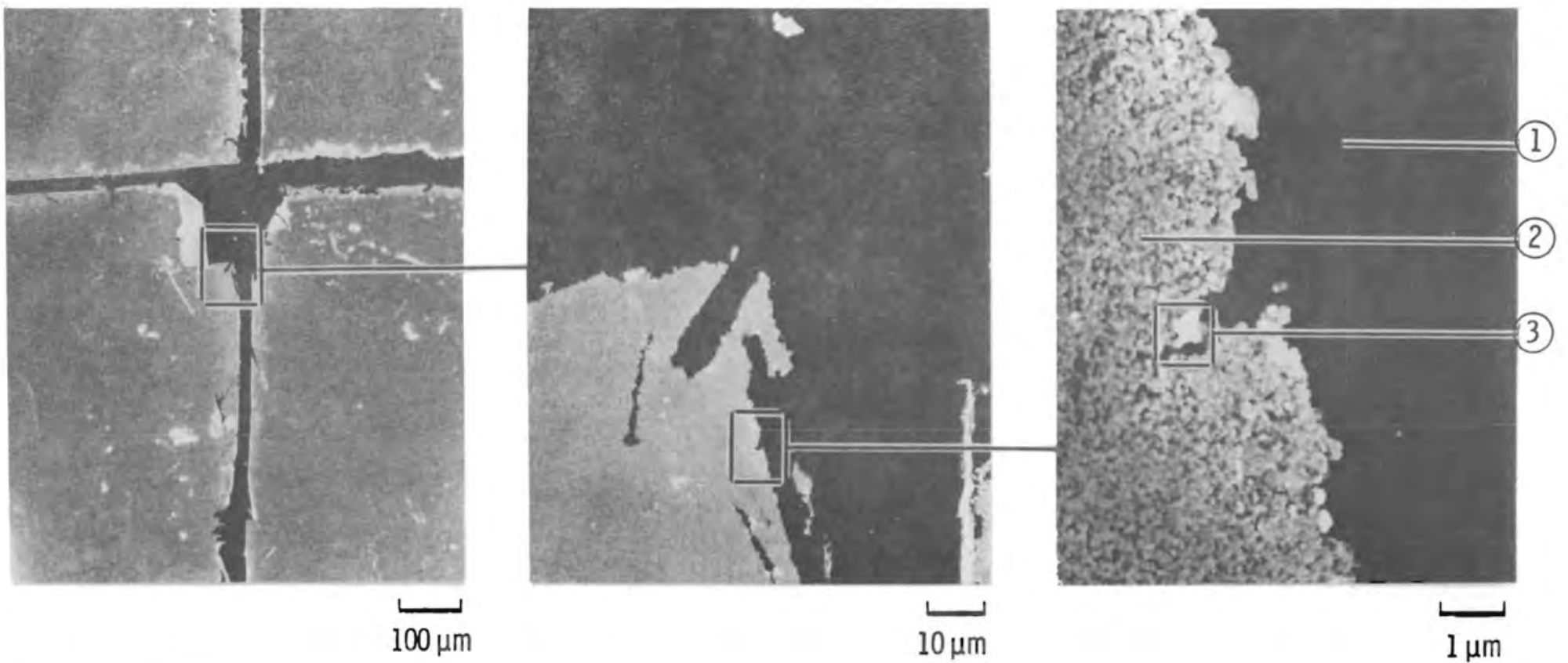

EDX ANALYSIS

1. GLASS AND THIN AGGLOMERATED Ag

2. GLASS

3. SAME AS I, BUT RICHER IN Ag, TRACE AMOUNT OF S

FIGURE 29. Commercially Silvered Mirrors after Moist $\mathrm{H}_{2} \mathrm{SO}_{4}$ Vapor Test 
$\underline{\mathrm{HNO}}_{3}$

Nitric acid tests gave results similar to those of the $\mathrm{HCl}$ tests in terms of quite uniform increase in degradation with increased exposure times, as is shown in Figure 30. The $\mathrm{HNO}_{3}$ test took somewhat longer than the $\mathrm{HCl}$ test. The test did produce uniform deterioration on each sample as seen in Figure 31. Two trials were done. In both trials the G samples performed the best.

SEM and EDX analysis showed a variety in both appearance and composition of the residues on the samples as seen in Figures 32 and 33 . Two samples were analyzed. One was thoroughly rinsed before analysis and the other was not rinsed so that the peeled paint layer would remain intact.

The rinsed sample in Figure 32 showed octahedral crystals with high lead content. Finger-like formations that were also high in lead were also visible. Both formations were tentatively idertified as lead salts. Some agglomerated silver remained, but no copper was left.

The unrinsed sample in Figure 33 showed other formations. The octahedral lead salt crystals were again present on both the paint and glass surfaces. Star-like formations high in silver and low in copper content were also present on the glass surface. Smaller particles high in copper and low in silver were found adjacent to the star formations. These deposits may have been soluble copper and silver salts that evaporated on the surface of the sample and were not rinsed off.

\section{Conclusion}

While the accelerated test results were somewhat ambiguous, the $C$ and $G$ mirror samples tended to perform the best on all the tests except the $\mathrm{H}_{2} \mathrm{SO}_{4}$ vapor test, where they exhibited the worst performance. The acid vapor tests were rather inconsistent from trial to trial. Changes in the temperature and humidity in the lab greatly affected the speed of the reaction of the acid vapors on the mirror samples. This may have adversely affected the reproducibility of the vapor tests. More trials need to be done for all the tests under carefully controlled environments to determine if more consistent and 


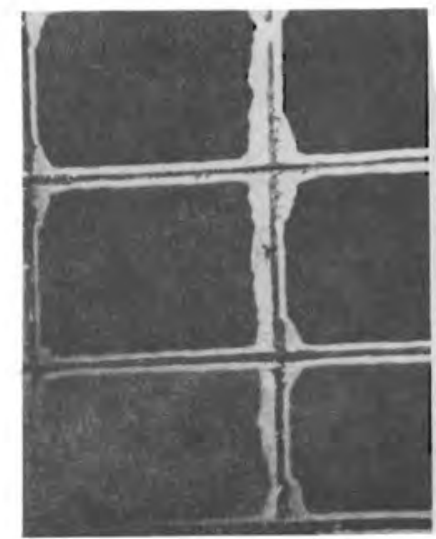

A. (5 MINUTES)

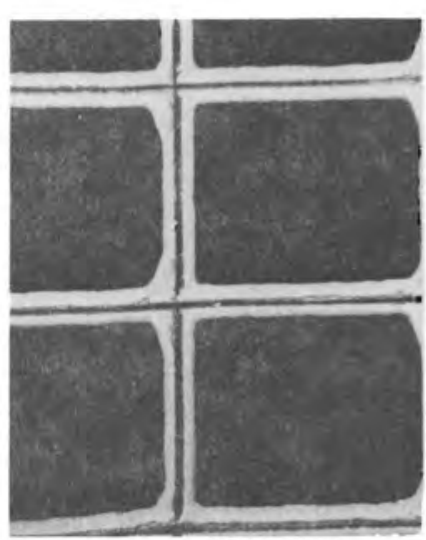

D. (20 MINUTES)

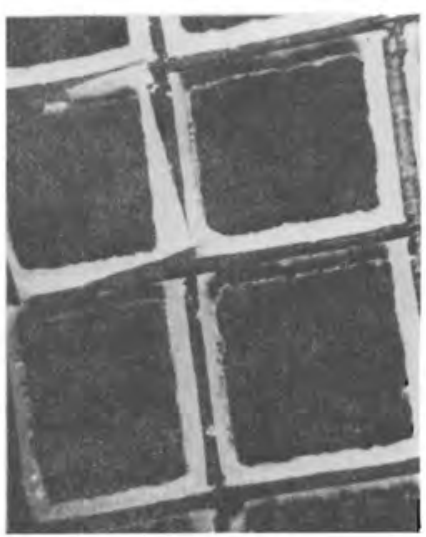

G. (35 MINUTES)

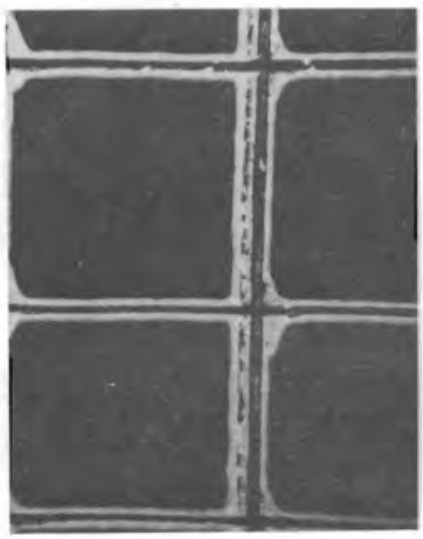

B. (10 MINUTES)

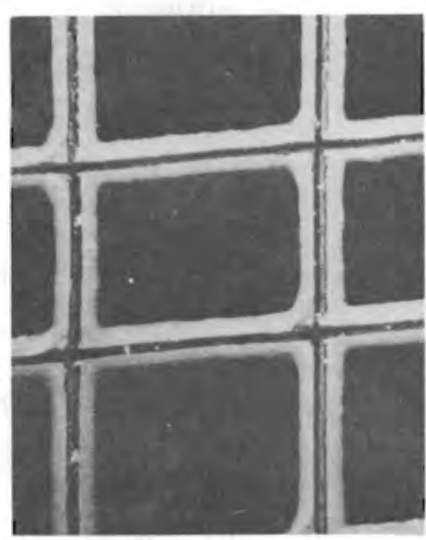

E. (25 MINUTES)

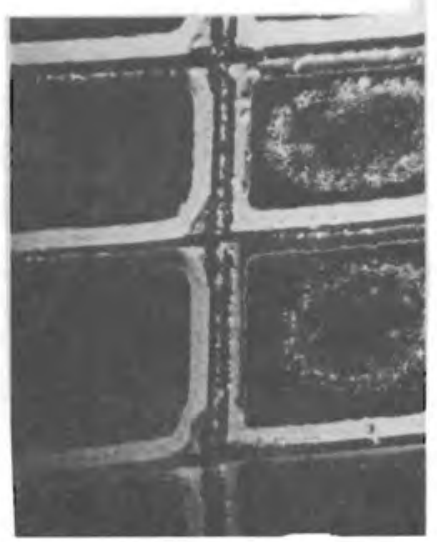

H. (40 MINUTES)

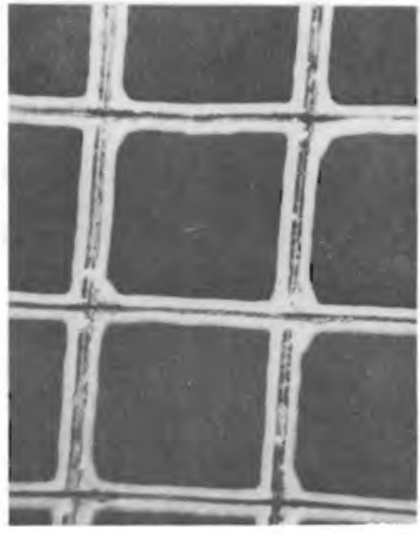

C. (15 MINUTES)

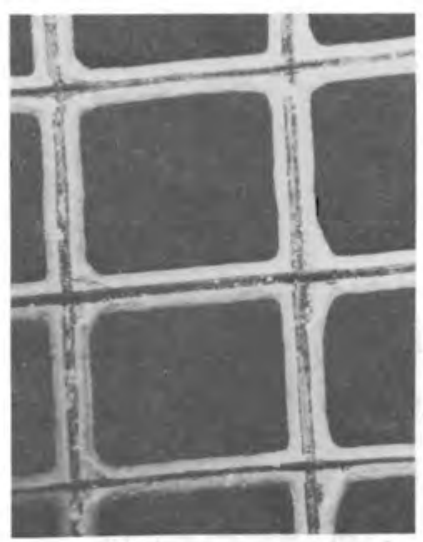

F. (30 MINUTES)

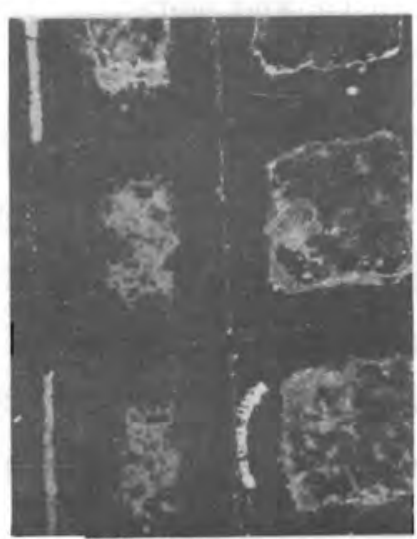

I. (45-50 MINUTES)

FIGURE 30. Progressive Degradation of Mirror Samples Exposed to $\mathrm{HNO}_{3}$ Vapor (Magnified View) 


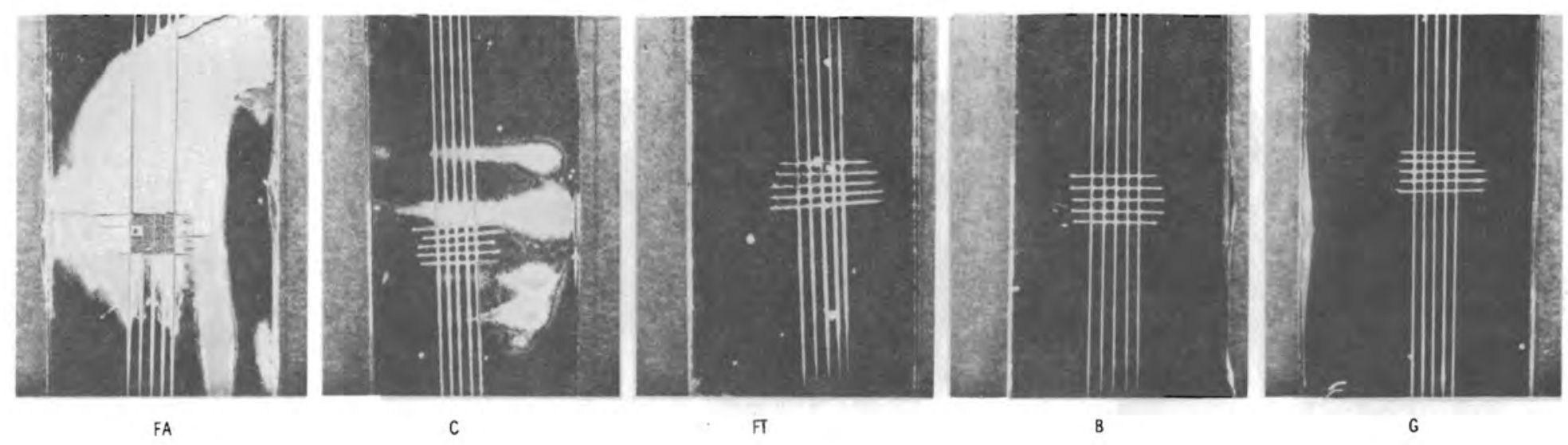

FIGURE 31. Commercially Silvered Mirrors ( $\mathrm{HNO}_{3}$ Test, $80 \mathrm{Min}$ ) 


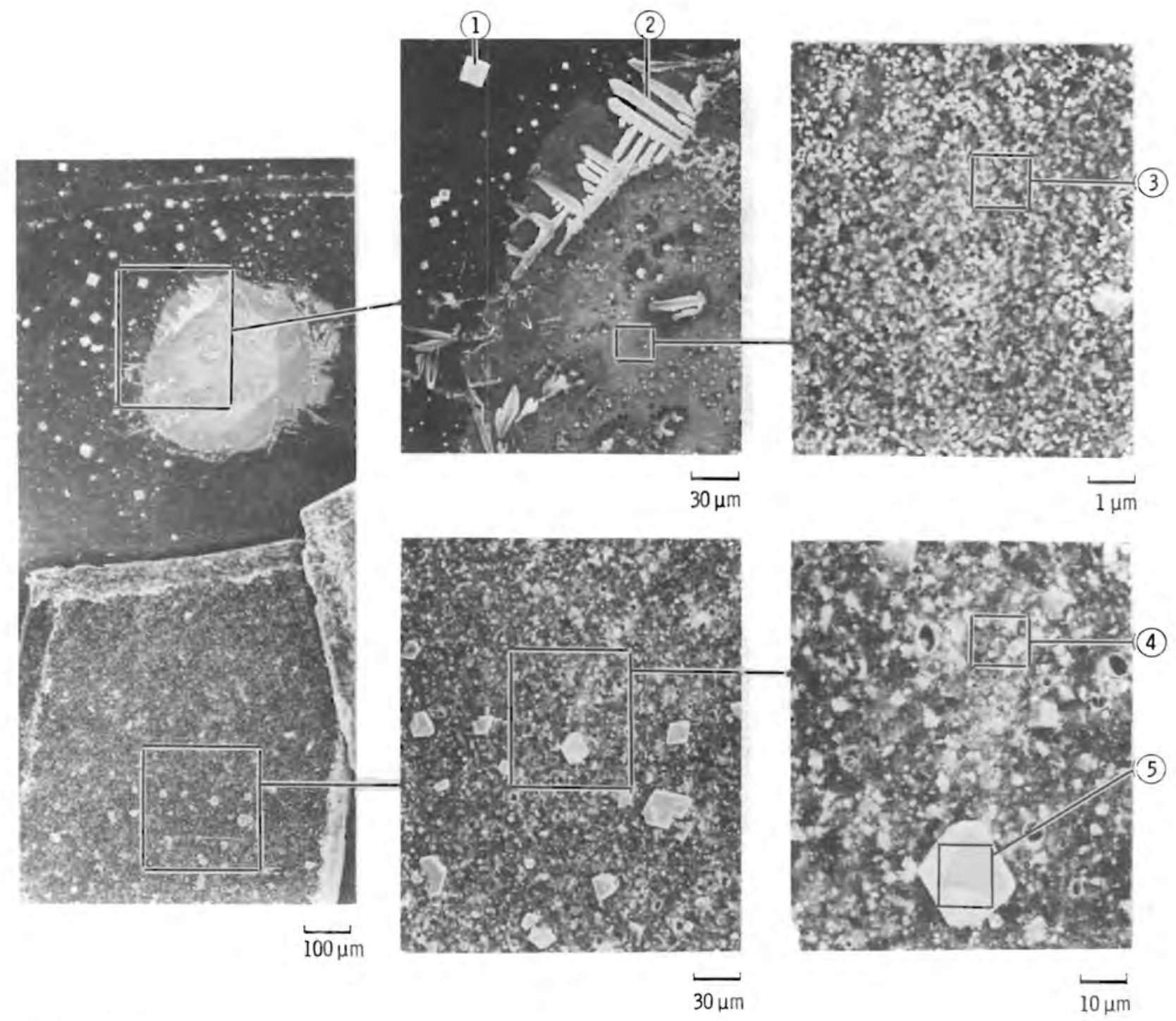

EDX ANALYSIS

1. Pb CRYSTAL ON GLASS + SMALL AMOUNT OF AI AND S

2. Pb, S AND SMALL AMOUNT OF AI AND Ag ON THE GLASS

3. GLASS, AGGLOMERATED Ag

4. PAINT (AI, Si, Pb, S, Ba)

5. SIMILAR TO 1, BUT MORE S

FIGURE 32. Commercially Silvered Mirrors after $\mathrm{HNO}_{3}$ Vapor Test. Sample rinsed in DI water prior to analysis. 


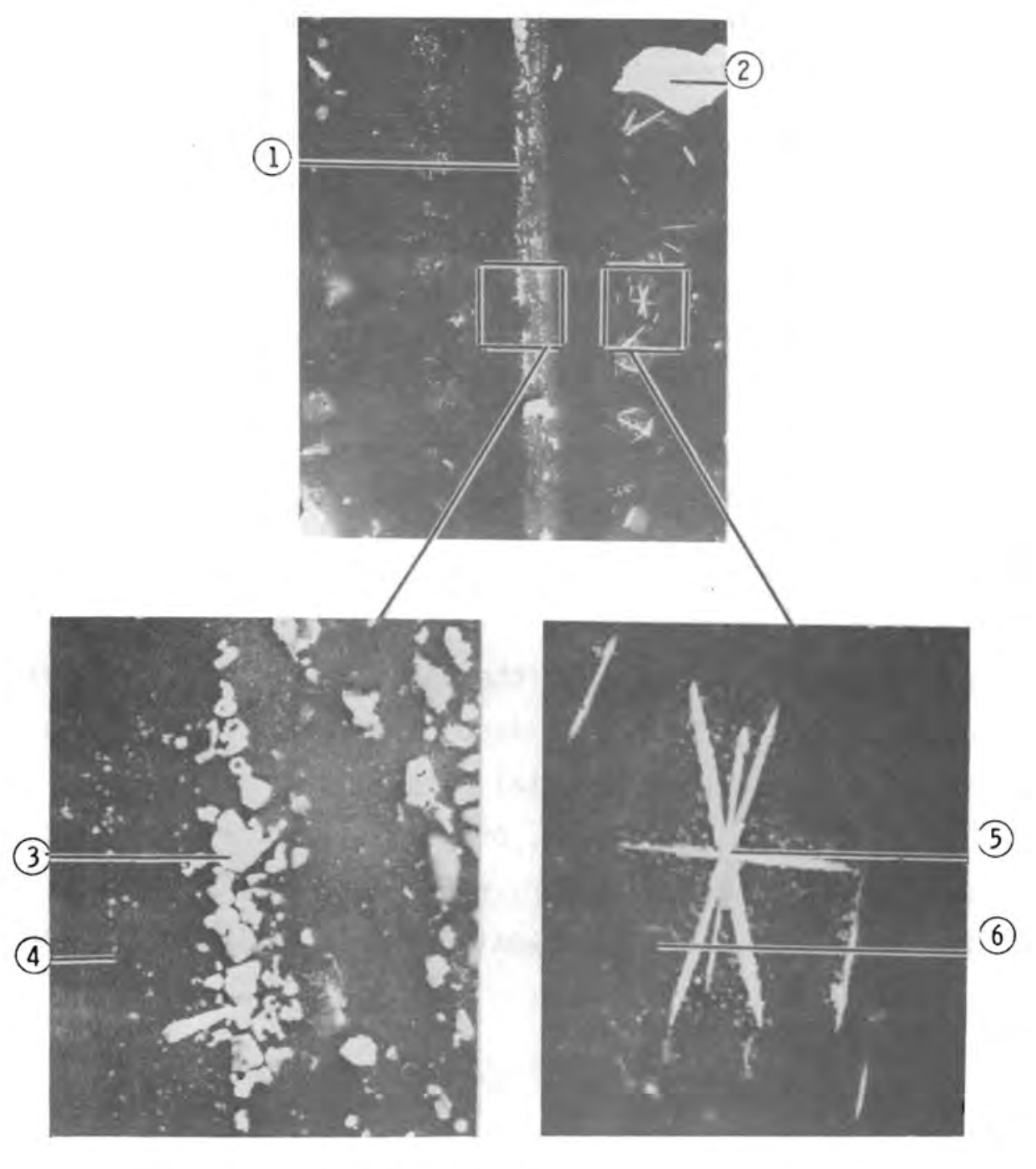

EDX ANALYSIS:

1. AREA OF INITIAL SCRIBE

2. LARGE PD CRYSTAL

3. GLASS, Pb, S AND SMALL AMOUNTS OF Al, Ag

4. GLASS

5. GLASS, Ag AND SMALL AMOUNTS OF $\mathrm{Cu}, \mathrm{Pb}, \mathrm{AI}$

6. GLASS, Cu AND SMALL AMOUNTS OF Ag, Al, Pb

FIGURE 33. Commercially Silvered Mirrors after $\mathrm{HNO}_{3}$ Vapor Test. Sample not rinsed prior to analysis. 
reproducible results are possible. SEM and EDX analysis, while interesting, did not provide enough information to accurately deduce reaction mechanisms or provide correlation to real time degradation phenomena.

\section{CONCLUSIONS AND RECOMMENDATIONS}

Both the adhesion and chemical vapor tests were performed in a preliminary attempt to assess the relative durability of commercial silver mirrors. Both types of tests, although totally qualitative in the final analysis because of the large scatter in the data and the uncertainty in the stress factors, did develop identifiable trends favoring a particular manufacturer's mirrors. The two types of tests sometimes favored different manufacturer's mirrors, but there appeared to be some correlation between the vapor test and the adhesion test.

Without a better understanding of the exact degradation mechanisms involved in natural weathering phenomena, it is impossible to demonstrate which kind of test is a better prediction tool (initial silver-to-glass adhesion strength resistance to specific chemical attack, or some yet unidentified test). The samples currently deployed on stationary racks throughout the United States may provide the first clue when their weathering characteristics are correlated with the type of testing reported here. 


\section{REFERENCES}

1. M. A. Lind, et al. 1979. Heliostat Mirror Survey and Analysis. PNL-3194, Pacific Northwest Laboratory, Richland, Washington.

2. R. M. A. Azzam and W. M. Bashara. 1977. Ellipsometry and Polarized Light. North Holland, Amsterdam.

3. K. Kuwahara, H. Hirota and N. Umemoto. 1978. "Adhesion Measurement on Thin Evaporation Films." Adhesion Measurement of Thin Films, Thick Films, and Bulk Coatings. ASTM STP 640. K. L. Mitta1, Ed. pp. 198-207.

4. R. Jacobsson. 1976. "Measurement of the Adhesion of Thin Films." Thin Solid Films. 34:191-199.

5. B. N. Chapman. 1974. "Thin Film Adhesion." J. Vac. Sci. Technol. 11(1):106-113. Jan/Feb.

6. C. Weaver. 1975. "Adhesion of Thin Films." J. Vac. Sci. Technol. 12(2):18-25. Jan/Feb.

7. K. L. Mittal. 1976. "Adhesion Measurement of Thin Films." Electrocomponent Science and Technology. 3:21-42. 


\section{DISTRIBUTION}

No. of

Copies

\section{OFFSITE}

\section{Technical Information Center}

B. Ackerman

Corning Glass Works

Ma in Plant, B1dg. 8-5

Corning, NY 14830

\section{Adams}

Jet Propulsion Laboratory

4800 Oak Grove Drive

Pasadena, CA 91108

J. F. Banas, 4722

Sandia Laboratories

Box 5800

A1buquerque, NM 87115

P. Bender

Ford Motor Company

Glass Division

3000 Renaissance Center

PO Box 43343

Detroit, MI 48253

M. Berry

Boeing Engr. and Const.

PO Box 3707

Seattle, WA 98124

J. Bigger

Electric Power Research Institute

PO Box 10412

Palo Alto, CA 93403

J. K. Blackburn

Carolina Mirror Corp.

PO Box 548, Elkin Rd.

N. Wilkesboro, NC 28659

F. Blake

Northrup, Inc., Blake Laboratory

Suite 306

7061 S. University Blvd.

Littleton, CO 80122
No. of

Copies

F. L. Bouquet

Jet Propulsion Laboratory

4800 Oak Grove Drive

Pasadena, CA 91108

G. E. Brandvold, 4713

Sandia Laboratories

Box 5800

Albuquerque, NM 87115

G. Braun

DOE Division of Solar Technology

20 Massachusetts Ave.

Washington, DC 20545

C. J. Brinker, 5845

Sandia Laboratories

Box 5800

Albuquerque, NM 87115

T. D. Brumleve, 8451

Sandia Laboratories

Livermore, CA 94550

V. Burolla

Sandia Laboratories

Livermore, CA 94550

Ken Busche

Busche Energy Systems

7288 Murdy Circle

Huntington Beach, CA 92647

B. Butler

Solar Energy Research Institute

1536 Cole Blvd.

Golden, CO 80401

P. Call

Solar Energy Research Institute 1536 Cole Blvd.

Golden, C0 80401 
No. of

Copies

R. E. Cambron

Springborn Laboratories

Water Street

Enfield, CT 06082

W. Carroll

Jet Propulsion Laboratory

4800 0ak Grove Drive

Pasadena, CA 91108

A. A. Churm

DOE Chicago Patent Group

9800 South Cass Avenue

Argonne, IL 60439

N. H. Clark, 1415

Sandia Laboratories

Box 5800

A1buquerque, NM 87115

G. Cottingham

Brookhaven National Laboratory

Upton, NY 11973

T. Coyle

Solar Energy Research Institute

1536 Cole Blvd.

Golden, CO 80401

D. Culler

Gardner Mirror Corp.

P0 Box 638, Hwy. 268E.

N. Wilkesboro, NC 28659

A. Czanderna

Solar Energy Research Institute

1536 Cole Blvd.

Golden, CO 80401

W. R. Delameter, 8451

Sandia Laboratories

Livermore, CA 94550

T. A. Dellin, 4723

Sandia Laboratories

Box 5800

A1buquerque, NM 87115
No. of

Copies

E. J. Dempsey

London Laboratories Limited

Box 3637

Woodbridge, CT 06525

R. J. Eagan, 5845

Sandia Laboratories

Box 5800

Albuquerque, NM 87115

C. R. Easton

McDonnel 1 Douglas

Astronautics Co.

5307 Bolsa Ave.

Huntington Beach, CA 92647

P. J. Eicker, 8326

Sandia Laboratories

Livermore, CA 94550

S. D. Elliott

DOE San Francisco

Operations Office

1333 Broadway

Wells Fargo Bldg.

Oakland, CA 94612

R. A. England

Martin Marietta

MS S0403

PO Box 179

Denver, C0 80201

H. E. Felix

Solaramics, Inc.

1301 E1 Segundo Blvd.

E1 Segundo, CA 90245

M. J. Fish, 8326

Sandia Laboratories

Livermore, CA 94550

C. R. Frownfelter

PPG Industries, Inc.

One Gateway Center

Pittsburg, PA 15222 
No. of

Copies

John Garate

General Electric

1 River Road

Schenectady, NY 12345

F. P. Gerstle, 5844

Sandia Laboratories

Box 5800

A1buquerque, NM 87115

R. L. Gervais

McDonne11 Douglas Astronautics

5301 Bolsa Ave.

Huntington Beach, CA 92647

R. N. Griffin

General Electric

1 River Road

Schenectady, NY 12345

R. Gillette

MS 9A-46

Boeing Engr. and Const.

PO Box 3707

Seattle, WA 98124

G. Gross

Solar Energy Research Institute

1536 Cole Blvd.

Golden, C0 80401

B. Gupta

Solar Energy Research Institute 1536 Cole Blvd.

Golden, C0 80401

M. U. Gutstein

DOE Division of Solar Technology

20 Massachusetts Avenue

Washington, DC 20545

W. Haller

Chief, Inorganic Glass Section

Institute for Materials

Research

National Bureau of Standards

Washington, DC 20234
No. of

Copies

T. R. Heaton

Martin Marietta Corporation

P. 0. Box 179

Denver, C0 80201

R. Hobbs

General Electric Company

P.0. Box 8661 - Room 7310

Philadelphia, PA 19101

P. L. Hofmann

Battelle

505 King Ave.

Columbus, $\mathrm{OH} 43201$

Richard Horton

General Electric

1 River Road

Schenectady, NY 12345

C. G. Howard

Booz, Allen \& Hamilton, Inc.

8801 E. Pleasant Valley Road

Cleveland, $\mathrm{OH} 44131$

Dennis Horgan

Solar Energy Research Institute

1536 Cole Blvd.

Golden, C0 80401

E. L. Katz

Aerospace Corporation

Solar Thermal Projects

Energy Systems Group

PO Box 92957

Los Angeles, CA 90009

Ernie Lam

Bechtel National Inc.

MS $50 / 16$

P.0. Box 3965

San Francisco, CA 94119

S. Lamensdorf

Binswanger Mirror Co.

1355 Lynnfield Rd., Suite 205

PO Box 17127

Memphis, TN 38117 
No. of

Copies

C. M. Lampert

Lawrence Berkeley Laboratory

Bldg. 62, Rm. 235

University of California

Berkeley, CA 94720

J. A. Leonard, 4725

Sandia Laboratories

Box 5800

Albuquerque, NM 87115

I. E. Lewis

Ford Aerospace

3939 Fabian Way

Palo Alto, CA 94303

V. L. Lindberg

Ford Glass Technical Center

25500 West Outer Drive

Lincoln Park, MI 48146

R. Livingston

Solar Energy Research Institute

1536 Cole Blvd.

Golden, C0 80401

K. Masterson

Solar Energy Research Institute 1536 Cole Blvd.

Golden, C0 80401

P. L. Mattern, 8342

Sandia Laboratories

Livermore, CA 94550

10 C. L. Mavis

Sandia Laboratories

Livermore, CA 94550

Mrs. McHugh

Sanders As sociates

95 Canal St., MS MER12-1214

Nashua, NH 03061

J. Megland

PRC 1 EAC

7600 01d Springhouse Rd.

McClaine, VA 22102
No. of

Copies

L. Melamed

DOE Division of Solar Technology

20 Massachusetts Avenue

Washington, DC 20545

B. E. Mi11s, 8315

Sandia Laboratories

Livermore, CA 94550

Walter Moore

Veda, Inc.

400 N. Mobil, B1dg. D

Camarillo, CA 93010

W. L. Morehouse, 8451

Sandia Laboratories

Livermore, CA 94550

R. E. Mutzberg

PPG Industries, Inc.

1377 Oakleigh Dr.

East Point, GA 30344

E. Nelson

ACUREX Corporation

485 Clyde Avenue

Mountain View, CA 94042

H. F. Norris, Jr., 8451

Sandia Laboratories

Livermore, CA 94550

L. P. 01dham

Martin Marietta Corp.

MS S8120

PO Box 179

Denver, C0 80201

R. Pettit, 5842

Sandia Laboratories

Box 5800

A1buquerque, NM 87115

J. A. Pietsch

Northrup, Incorporated

302 Nichols Drive

Hutchins, TX 75141 
No. of

Copies

J. Schrauth

Jena Glaswerk Schott

\& Gen., Inc.,

11 East 26th Street

New York, NY 10010

J. C. Schumacher

Schumacher \& Associates

2550 Fair Oaks Blvd., Suite 120

Sacramento, CA 95825

R. N. Schweinberg

DOE San Francisco Operations Office

1333 Broadway

Wells Fargo Bldg.

Oakland, CA 94612

J. Shelby

Sandia Laboratories

Livermore, CA 94550

A. F. Shoemaker

Corning Glass Works

Corning, NY 14830

A. C. Skinrood

Sandia Laboratories

Livermore, CA 94550

D. A. Steinmeyer

McDonnell Douglas Astronautics

5301 Bolsa Avenue

Huntington Beach, CA 92647

Howard Sund

Ford Aerospace

3939 Fabian Way, T33

Palo Alto, CA 94303

H. R. Swift

Libby Owens Ford Company

Technical Center

1701 E. Broadway

Toledo, $\mathrm{OH} 43605$

John Thornton

Solar Energy Research Institute

1536 cold Blvd.

Golden, CO 80401
No. of

Copies

\author{
W. Tomlinson \\ Environmental Library \\ 758 Eddy St. \\ Univ. of Montana \\ Missoula, MT 59812 \\ P. Tremblay \\ Foster-Miller Associates \\ 135 Second Ave. \\ Waltham, MA 02154 \\ R. Turner \\ Falconer Plate Glass Corp. \\ 500 S. Work Street \\ Falconer, NY 14733 \\ C. N. Vittitoe, 4231 \\ Sandia Laboratories \\ Box 5800 \\ Albuquerque, NM 87115
}

10 J. Vitko

Sandia Laboratories

Livermore, CA 94550

R. R. Walters

E. Systems

Energy Technology Center

PO Box 6118

Dallas, TX 75222

J. D. Walton, Jr.,

Engineering Experiment Station

Georgia Institute of Technology

Atlanta, GA 30332

R. C. Wayne, 8450

Sandia Laboratories

Livermore, CA 94550

L. Weinstein

McDonnell Douglas

Astronautics Co.

5301 Bolsa Ave.

Huntington Beach, CA 92647 
No. of

Copies

S. White, 8451

Sandia Laboratories

Livermore, CA 94550

D. Wiley

Guardian Industries Corp.

43043 W. Nine Mile Road

Northville, MI 48167

10 W. G. Wilson

Sandia Laboratories

Livermore, CA 94550

G. Yaeger

Buckmin Industries

1485 E. Curtis

Reedley, CA 93654

\section{FORE IGN}

T. Hi sakado

SUNSHINE Project Operation Bureau

5-8-2, Marunouchi, Chiyoda-ku

Tokyo, Japan

A. K. Seth

Solar Energy Group

Centre of Energy Studies

Indian Institute of Technology

Haug Khas, New Dehli

110029, India

T. Tanaka

Electrotechnical Laboratory

5-4-1, Mukodai, Tanashi

Tokyo, Japan
No. of

Copies

ONSITE

2 DOE Richland Operations Office

H. E. Ransom

R. Stewart

68 Pacific Northwest Laboratory

C. Q. Buckwalter

W. J. Coleman

L. S. Dake

J. L. Daniel

K. Drumheller

J. S. Hartman

M. A. Lind (50)

A. M. Sutey

Publishing Coordination

Technical Information JO 